\title{
Seismic Stability of St. Stephen Hydropower Plant, South Carolina
}

Robert M. Ebeling, Robert L. Hall, Ralph W. Strom, Donald E. Yule, and Mostafiz Chowdhury
February 2002

(Revised November 2006)

\section{Downstream view}


ERDC LR-02-1

February 2002

(Revised November 2006)

\title{
Seismic Stability of St. Stephen Hydropower Plant, South Carolina
}

\author{
Robert M. Ebeling \\ Information Technology Laboratory \\ U.S. Army Engineer Research and Development Center \\ 3909 Halls Ferry Road \\ Vicksburg, MS 39180-6199 \\ Robert L. Hall, Donald E. Yule, and Mostafiz Chowdhury \\ Geotechnical and Structures Laboratory \\ U.S. Army Engineer Research and Development Center \\ 3909 Halls Ferry Road \\ Vicksburg, MS 39180-6199 \\ Ralph W. Strom \\ 9474 S. E. Carnaby Way \\ Portland, OR 97266
}

Final report

Approved for public release; distribution is unlimited. [or a restricted statement]

Prepared for U.S. Army Engineer District, Charleston

Charleston, SC 29403-5107 


\begin{abstract}
A performance-based analysis was used to assess the seismic performance of St. Stephen Powerhouse erection bay. Two site-specific design response spectra were used to evaluate the structure. These included a 2,475-year probabilistic earthquake event and a deterministic Maximum Credible Earthquake plus one standard deviation event. The St. Stephen Powerhouse superstructure is vulnerable to collapse for earthquake hazards with return periods greater than 500 years. The structure does not meet the basic safety objective (collapse prevention) of the Federal Emergency Management Agency "Prestandard and Commentary for the Seismic Rehabilitation of Buildings," FEMA 356-357.
\end{abstract}

DISCLAIMER: The contents of this report are not to be used for advertising, publication, or promotional purposes. Citation of trade names does not constitute an official endorsement or approval of the use of such commercial products. All product names and trademarks cited are the property of their respective owners. The findings of this report are not to be construed as an official Department of the Army position unless so designated by other authorized documents. 


\section{Contents}

Figures and Tables................................................................................................................

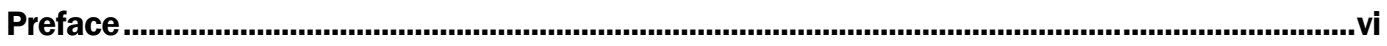

Unit Conversion Factors..........................................................................................................................vii

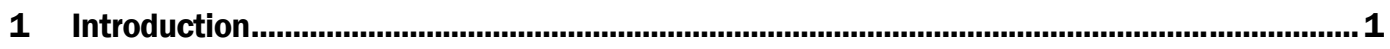

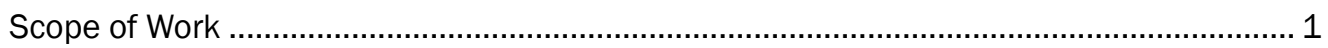

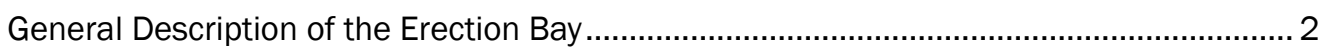

Structure Idealization for Seismic Evaluation................................................................... 8

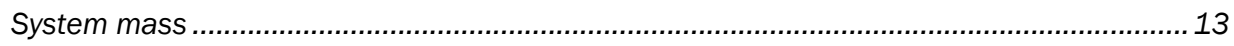

Material properties....................................................................................................... 14

Sectional properties for the erection bay wall elements ................................................. 16

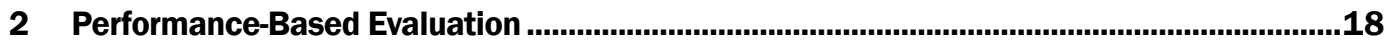

Procedures Used to Assess Structure Displacement Demand......................................... 18

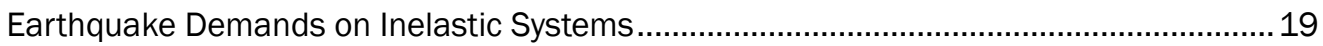

Ductility Capacity of Reinforced Concrete Structures ....................................................... 24

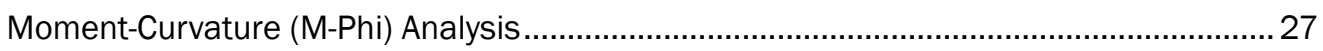

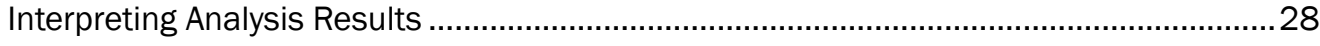

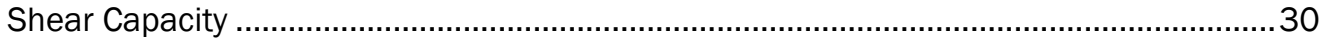

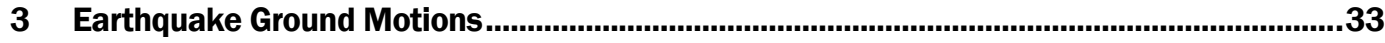

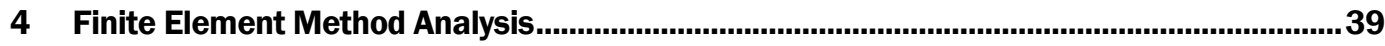

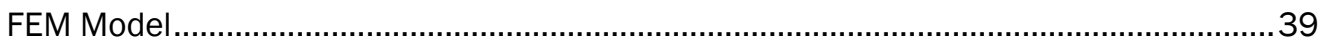

Earthquake Demands ......................................................................................... 44

5 Summary of Analysis Results for St. Stephen Erection Bay Walls ......................................48

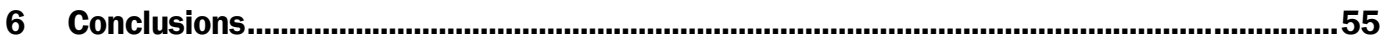

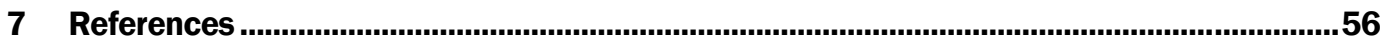

Appendix A

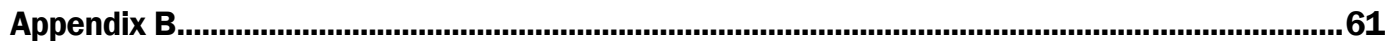

\section{Report Documentation Page}




\section{Figures and Tables}

\section{Figures}

Figure 1-1. Cooper River Rediversion Project power plant - general arrangement (Plan-

El 2.0)

Figure 1-2. Longitudinal section through the middle of the powerhouse, Cooper River Rediversion Project power plant

Figure 1-3. Transverse section through the middle of the erection bay, Cooper River Rediversion Project power plant. 5

Figure 1-4. A view of the overhead crane and corbel arrangement looking at the upstream wall from the erection bay platform at el 57.0 ................................................................. 6

Figure 1-5. A view of the generator bays from the erection bay platform at el 57.0 ......................... 7

Figure 1-6. Downstream view of the St. Stephen Powerhouse looking from the access

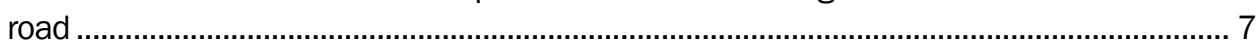

Figure 1-7. Upstream view of the St. Stephen Powerhouse looking from the fish-lift side.................. 8

Figure 1-8. Upstream view of the intake deck looking from the fish-lift side ................................... 9

Figure 1-9. Upstream T-beam connection: shim plates welded to embedded wall (an ideal hinge condition)

Figure 1-10. Downstream T-beam connection: T-beam bearing plate rests on Neoprene pad, bolt through plate with slotted holes (an ideal roller condition).

Figure 2-1. Performance and structural deformation demand for ductile structures.......................19

Figure 2-2. Earthquake demands on inelastic structures............................................................20

Figure 2-3. Characteristic ground motion. ......................................................................................... 21

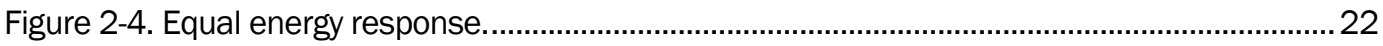

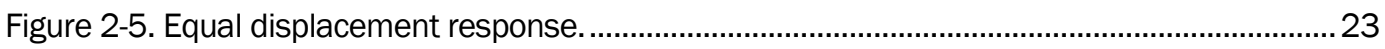

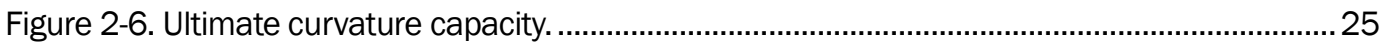

Figure 2-7. Concentrated mass model.......................................................................................... 27

Figure 2-8. Results of M-Phi analyses for St. Stephen erection bay walls...................................... 29

Figure 2-9. Concrete shear strength versus ductility. .................................................................. 32

Figure 3-1. NEHRP USGS National Probabilistic Seismic Hazard Map for PGA with 2,475-

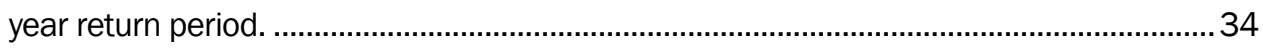

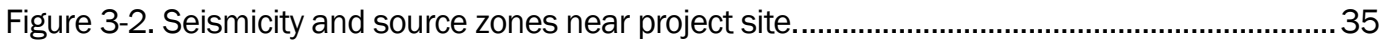

Figure 3-3. Earthquake response spectra for St. Stephen Powerhouse............................................ 37

Figure 4-1. Beam-column model of the erection bay...................................................................40

Figure 4-2. First mode of vibration for erection bay. .........................................................................4 42

Figure 4-3. Second mode of vibration for erection bay............................................................... 42

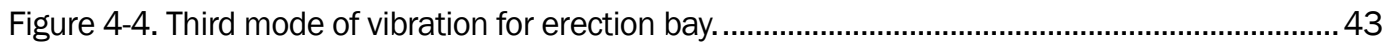

Figure 4-5. Eighth mode of vibration for erection bay................................................................... 43

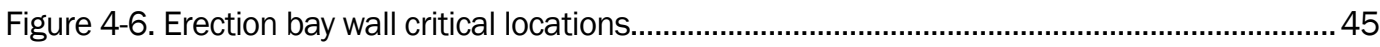


Figure 5-1. Erection bay superstructure plastic hinge locations (yield regions).

\section{Tables}

Table 1-1. Sectional properties for wall elements $f_{c a}{ }^{\prime}=4,500$ psi (Actual compressive strength). 16

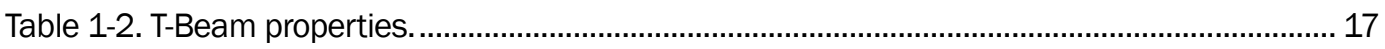

Table 2-1. Demand to capacity evaluations.................................................................................. 30

Table 3-1. Probabilistic acceleration response spectra per 1996 National Earthquake Hazards Reduction Program (NEHRP) (from Franket et al. 1996)...................................... 37

Table 3-2. Probabilistic acceleration response spectra, maximum considered earthquake for site classes $A$ and B, return period = 2,475 years (from FEMA 1997b)...................... 38

Table 3-3. Deterministic acceleration response spectra (from Toro et al. 1997)..............................38

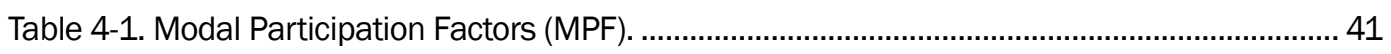

Table 4-2. Member demands (SAP2000) for both NEHRP 2,474-year and MCE events for ideal and nonideal boundary conditions of the 66 -ft-wide erection bay. .............................46

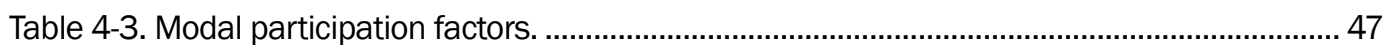

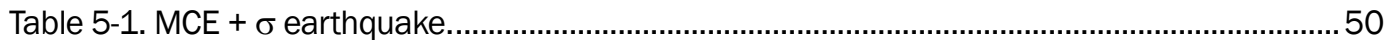

Table 5-2. NEHRP 2,475-year earthquake demands. .................................................................50

Table 5-3. NEHRP 1,000-year earthquake demands.................................................................... 51

Table 5-4. NEHRP 475-year earthquake demands.................................................................. 51

Table 5-5. Sample calculation for upstream wall displacement ductility capacity, Point 1 (el 86). 


\section{Preface}

This report describes the seismic performance evaluation of St. Stephen Powerhouse located in the Cooper River Rediversion Project in South Carolina conducted by the U.S. Army Engineer Research and Development Center (ERDC), Vicksburg, MS.

The research described in this report was performed at the request of the U.S. Army Engineer District, Charleston. Mr. Wayne A. Bieganousky, Chief of the Geotechnical, Materials and Site Work Section, Charleston District, supervised the project for the Charleston District. Dr. Robert M. Ebeling of the Information Technology Laboratory (ITL), Vicksburg, MS, ERDC, is the Principal Investigator of this research effort.

This research was jointly conducted and the report prepared by Dr. Robert M. Ebeling, Computer-Aided Engineering Division (CAED), ITL; Dr. Robert L. Hall, Chief, Geosciences and Structures Division, Geotechnical and Structures Laboratory (GSL), ERDC; Ralph W. Strom, Portland, OR; Donald E. Yule, Geotechnical and Earthquake Engineering Branch, Geosciences and Structures Division; and Dr. Mostafiz R. Chowdhury, formerly of the Structural Mechanics Branch, Geosciences and Structures Division, GSL. Dr. Ebeling authored the scope of work for the research effort discussed in this report.

The research was monitored by Dr. Ebeling, under the supervision of ITL personnel Dr. Charles R. Welch, Chief of Engineering and Informatics Systems Division; Mr. David R. Richards, Technical Director; Dr. Deborah F. Dent, Assistant Director; and Dr. Jeffery P. Holland, Director; and GSL personnel Dr. Hall; Dr. Joseph P. Koester, Chief, Geotechnical and Earthquake Engineering Branch, Geosciences and Structures Division; Dr. Michael K. Sharp, Acting Technical Director for Civil Works Infrastructure; Dr. William P. Grogan, Assistant Director; and Dr. David W. Pittman, Director.

At the time of publication of this report, Dr. James R. Houston was Director of ERDC, and COL James R. Rowan was Commander and Executive Director. 


\section{Unit Conversion Factors}

\begin{tabular}{|l|c|l|}
\hline Multiply & By & To Obtain \\
\hline cubic inches & $1.6387064 \mathrm{E}-05$ & cubic meters \\
\hline feet & 0.3048 & meters \\
\hline foot-kips & 1.356 & kilonewton-meters \\
\hline inches & 0.0254 & meters \\
\hline kips (1,000 lbf) & $4,448.222$ & newtons \\
\hline kips per foot & 14.5939 & kilonewtons per meter \\
\hline kips per square foot & 47.88026 & megapascals \\
\hline kips per square inch & 6.894757 & megapascals \\
\hline pounds (force) per square inch & 6.894757 & kilopascals \\
\hline pounds (mass) & 0.45359237 & kilograms \\
\hline pounds (mass) per square foot & 4.882428 & kilograms per square meter \\
\hline square inches & 6.4516 E-04 & square meters \\
\hline tons (2,000 pounds, mass) & 907.1847 & kilograms \\
\hline
\end{tabular}




\section{Introduction}

\section{Scope of Work}

At the request of the U.S. Army Engineer District, Charleston, the U.S. Army Engineer Research and Development Center conducted the seismic performance evaluation of St. Stephen Powerhouse located in the Cooper River Rediversion Project in South Carolina. The structure, about $60 \mathrm{~km}$ north of Charleston, SC, consists of a powerhouse reinforced concrete structure founded on rock and flanked by rolled-fill earth embankments. This report summarizes the seismic evaluation of the erection bay superstructure.

A performance-based approach was used for the seismic evaluation to determine the risk of superstructure collapse during a major earthquake. In the performance-based approach, superstructure displacement ductility capacities are compared to earthquake displacement ductility demands. Collapse prevention performance requires that collapse of the structure be prevented regardless of the level of damage. Resistance can decrease with increasing displacements provided the structure will not collapse when subjected to extreme earthquake events. The powerhouse superstructure is assumed to perform satisfactorily (collapse prevented) if member flexural displacement ductility capacities are greater than displacement ductility demands, and if shear capacities are greater than shear demands.

The erection bay is more vulnerable to earthquake ground motions than are the generator bays. The erection bay is assumed to be critical because of the additional hazard associated with the possibility of derailment of the overhead crane. The overhead crane will likely be parked in the erection bay at the time of a major earthquake event.

Displacements and displacement ductility demands are determined by elastic response spectrum analysis. FEMA 273, "NEHRP (National Earthquake Hazards Reduction Program) Guidelines for the Seismic Rehabilitation of Buildings" (Federal Emergency Management Agency (FEMA) 1997a) considers this to be a Linear Dynamic Procedure (LDP) type analysis. Earthquakes considered in the collapse prevention analysis are the maximum considered earthquake, a probabilistic event with a return period of 2,475 years, and the Maximum Credible Earthquake 
(MCE), a deterministic event. The mean + one standard deviation event was used for the MCE analysis.

Elastic response spectrum analyses provide both force and displacement demands. A SAP200o finite element method analysis (Computers and Structures, Inc., 1997) provided the elastic seismic demands for the two design response spectra.

\section{General Description of the Erection Bay}

A general layout of the powerhouse is presented in Figures 1-1 and 1-2. As seen in these figures, St. Stephen Powerhouse consists of three generator bays and one erection bay. Figure 1-1 shows the in-plan layout of the power plant at elevation (el) 2.o. In this figure, looking upstream, the 66 - $\mathrm{ft}$-wide erection bay is seen on the left of the generation bays. ${ }^{1}$

Figure 1-2 shows a longitudinal section of the powerhouse, taken at a section along the powerhouse centerline. This figure shows the elevations of different floor levels and the general layout of the erection bay. A seismic performance evaluation of the erection bay is conducted in this investigation.

Figure 1-3 is a transverse section through the middle of the erection bay. As seen in this figure, the main erection bay has several floor levels over a massive concrete base that extends from el 18.0 to el -41 . Precast prestressed T-beams at el 93.92 compose the roof system. Field observation reported that the actual T-beam dimensions agree with the Precast/Prestressed Concrete Institute (PCI) standard Type B load table properties (PCI 1999). Therefore, the standard PCI 8ST32 T-beam is used for the seismic analysis. An 8-ft-wide 8ST32 has a depth of 32 in., a unit weight of $560 \mathrm{lb}$ per linear foot, a section modulus of 4,667 in. 3 for the top and 1,619 in. 3 for the bottom, and a cross-sectional area of 506 in. ${ }^{2}$

\footnotetext{
${ }^{1} \mathrm{~A}$ table of factors for converting non-SI units is found on page vii.
} 


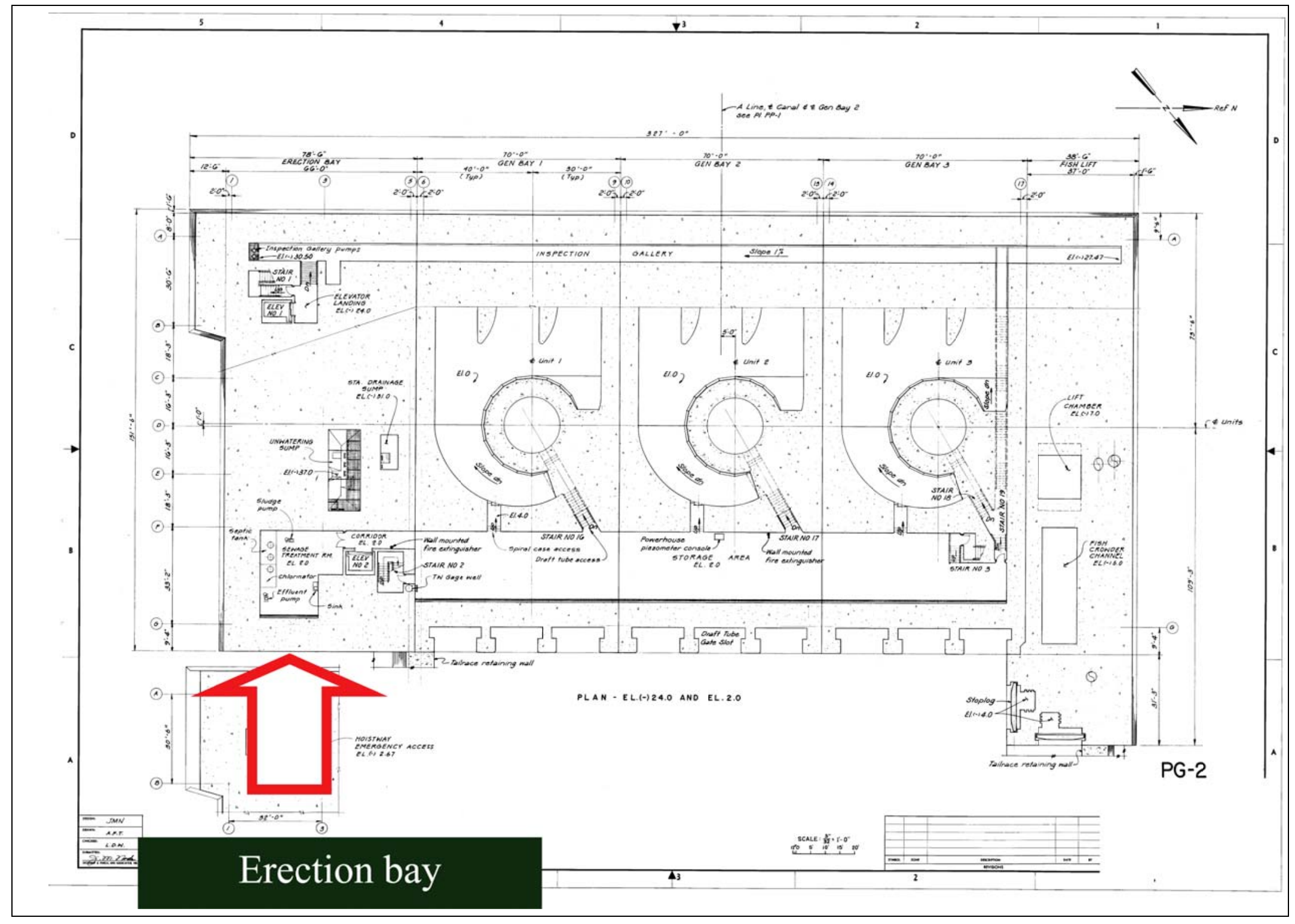

|

Figure 1-1. Cooper River Rediversion Project power plant - general arrangement (Plan- El 2.0) 


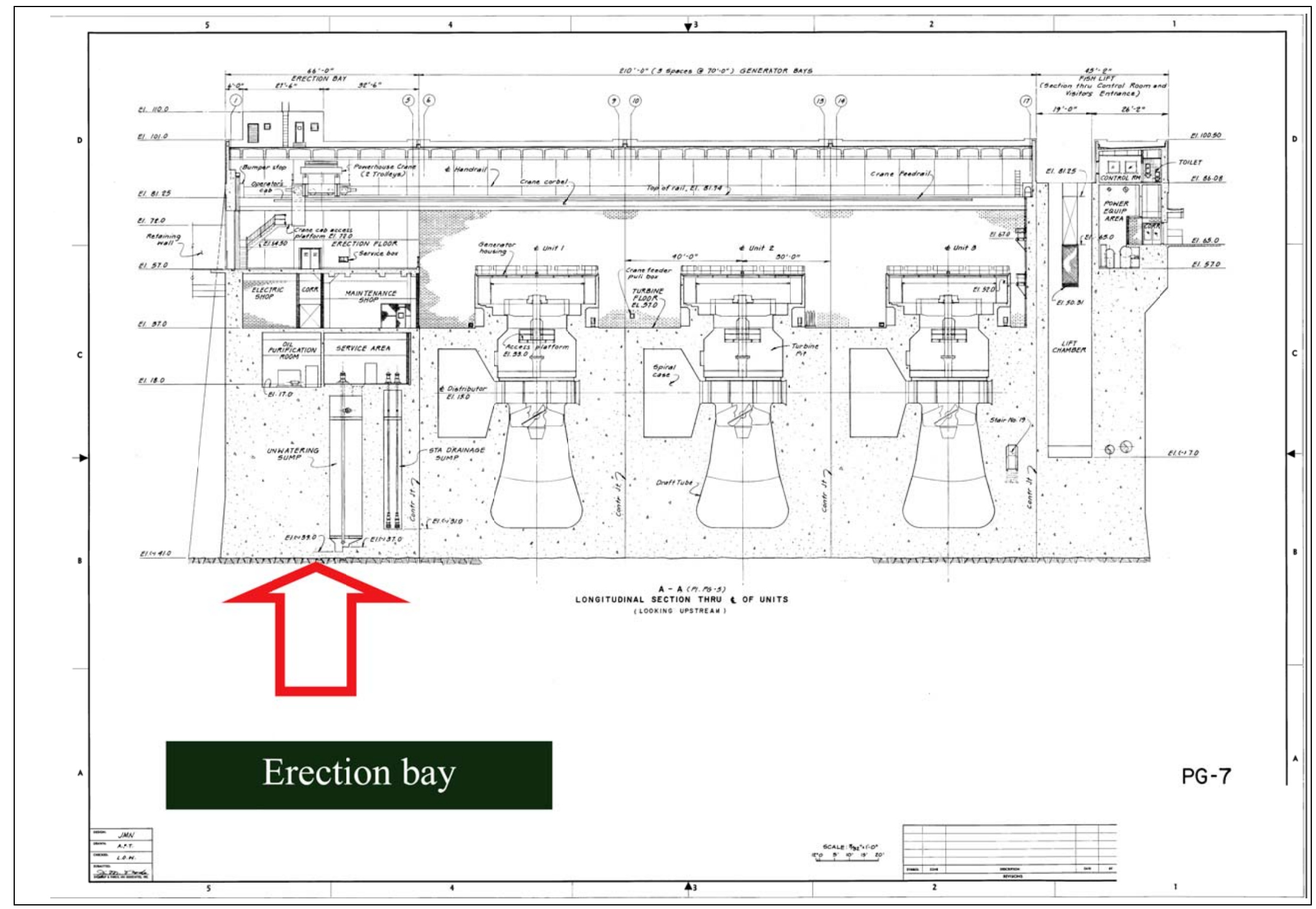

Figure 1-2. Longitudinal section through the middle of the powerhouse, Cooper River Rediversion Project power plant 


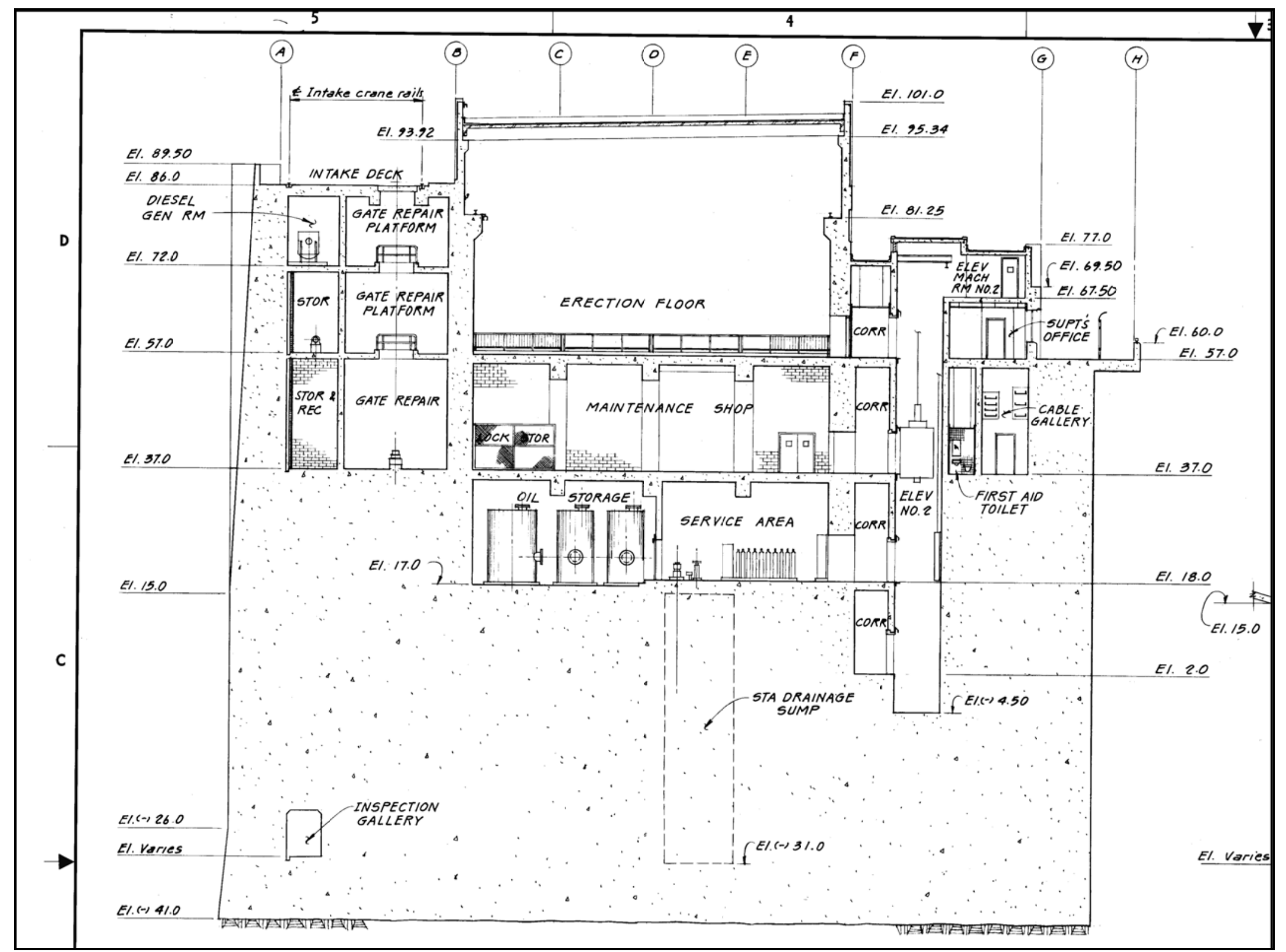

Figure 1-3. Transverse section through the middle of the erection bay, Cooper River Rediversion Project power plant 
Figures 1-4 and 1-5 show the inside views of the powerhouse from the erection floor at el 57.0. A 135/20-ton overhead crane, manufactured by Broadline Corporation, Richmond, CA, is supported by corbels located on the face of the upstream and downstream walls (el 81.25). Internal documents indicate that the overhead crane used at the site weighs $152,200 \mathrm{lb}$. The corbel seat width must be large enough to prevent the crane from dropping to the generator floor (wide enough to prevent unseating) during a major earthquake event. The crane travels on rails mounted 14 in. from the corbel face. Displacement demands on the wall at the corbel location therefore must be less than 14 in. to prevent unseating.

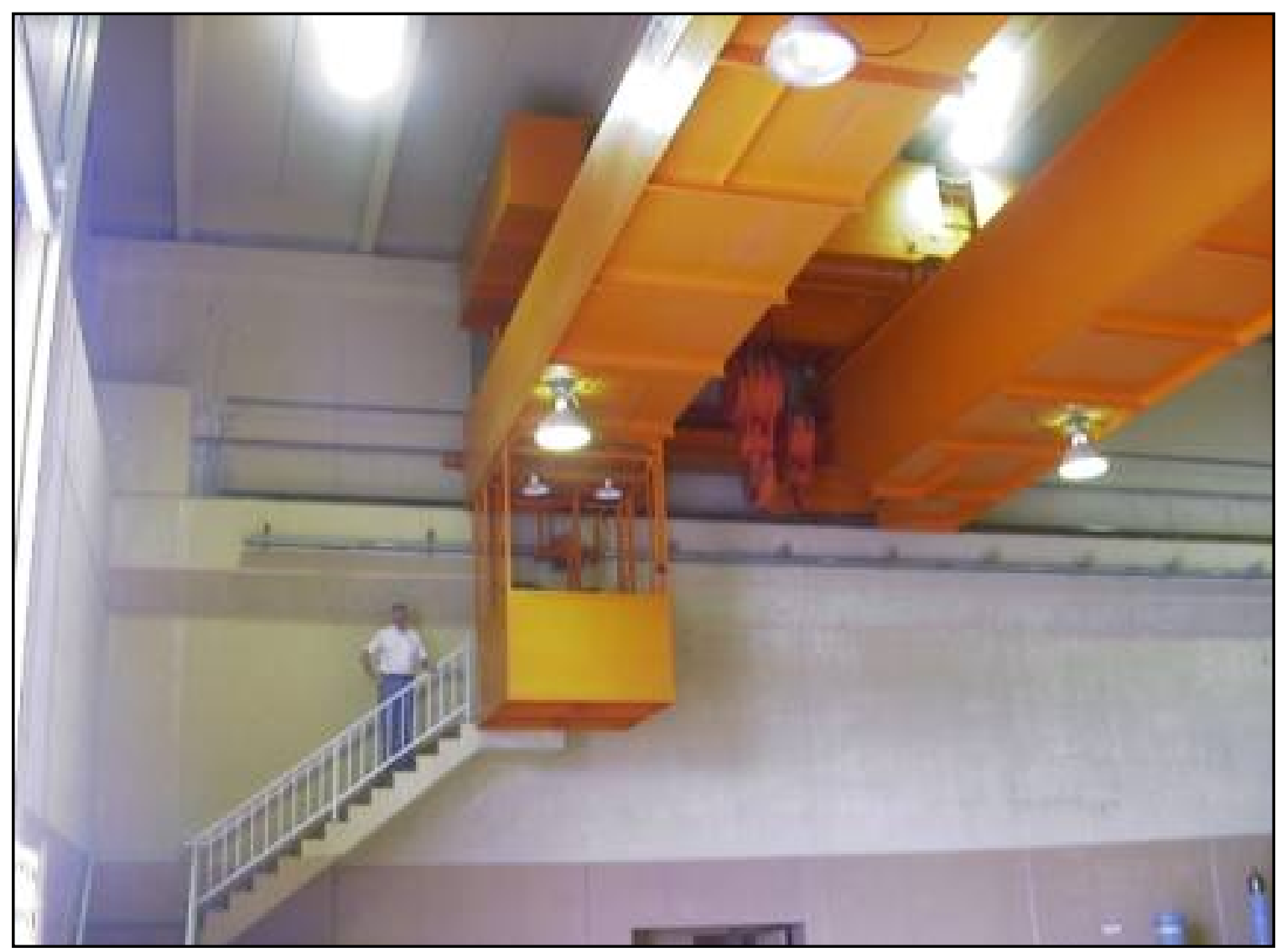

Figure 1-4. A view of the overhead crane and corbel arrangement looking at the upstream wall from the erection bay platform at el 57.0

The downstream and upstream faces of the powerhouse are shown in Figures 1-6 and 1-7, respectively. Figure 1-8 shows the deck area over upstream intake. 

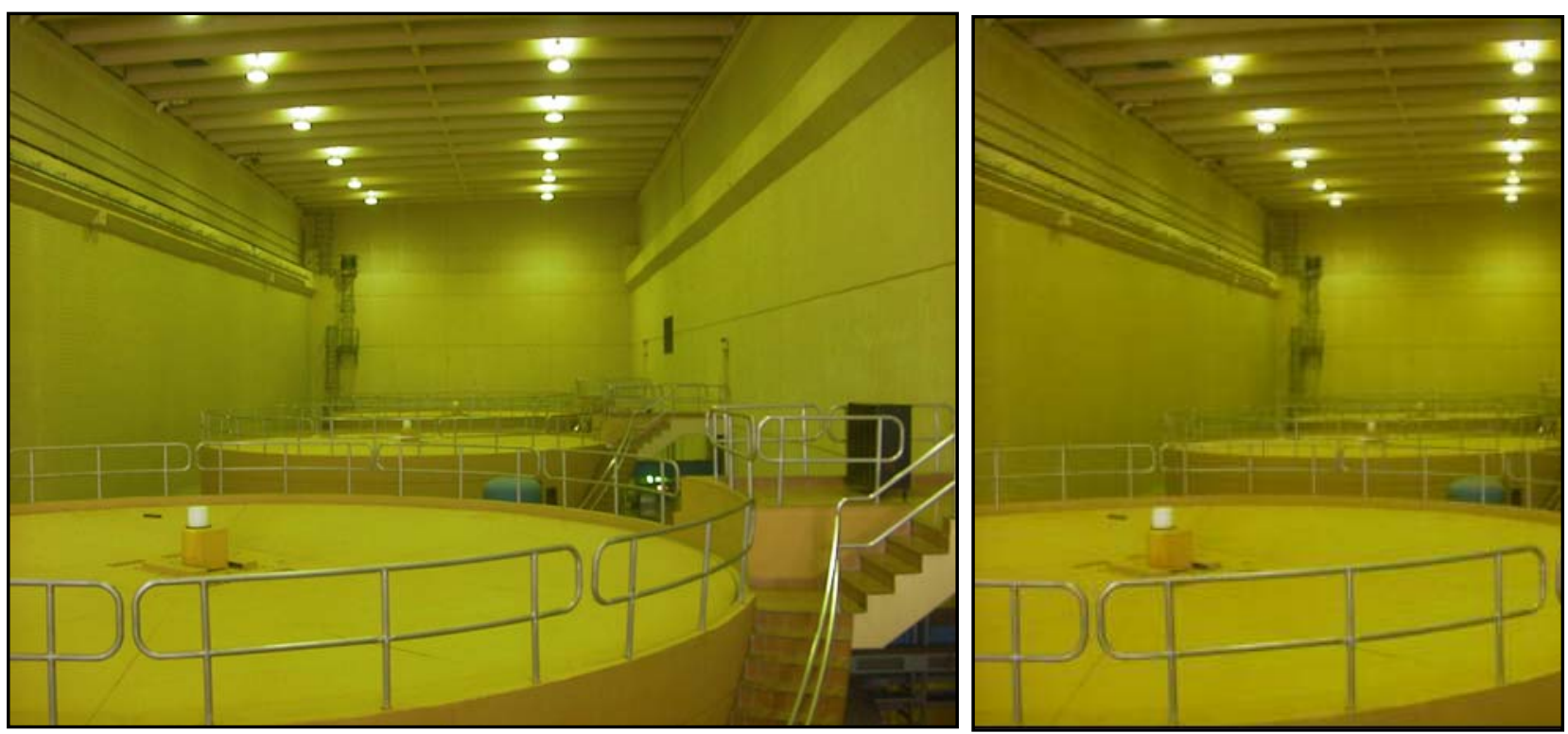

Figure 1-5. A view of the generator bays from the erection bay platform at el 57.0

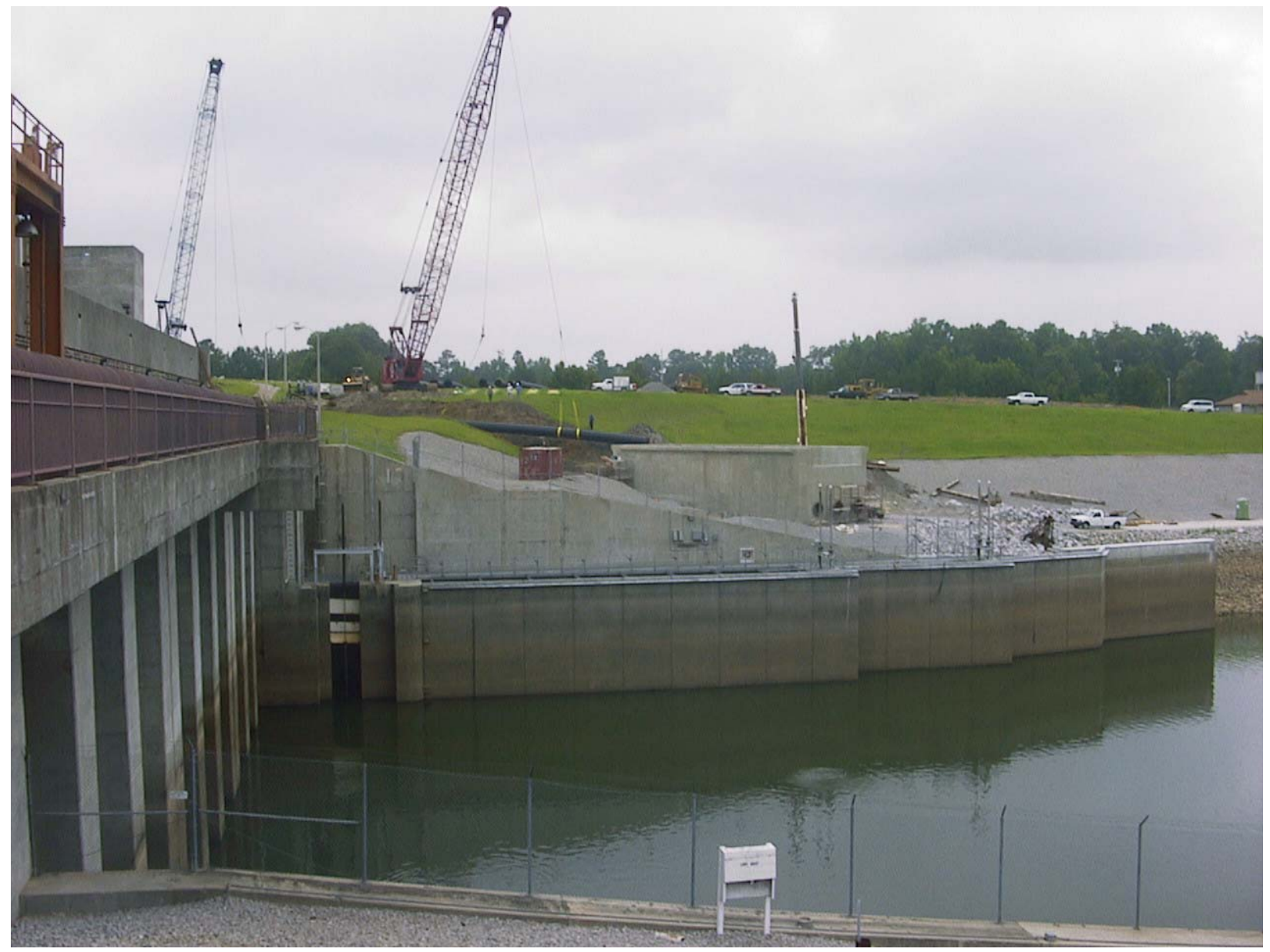

Figure 1-6. Downstream view of the St. Stephen Powerhouse looking from the access road 


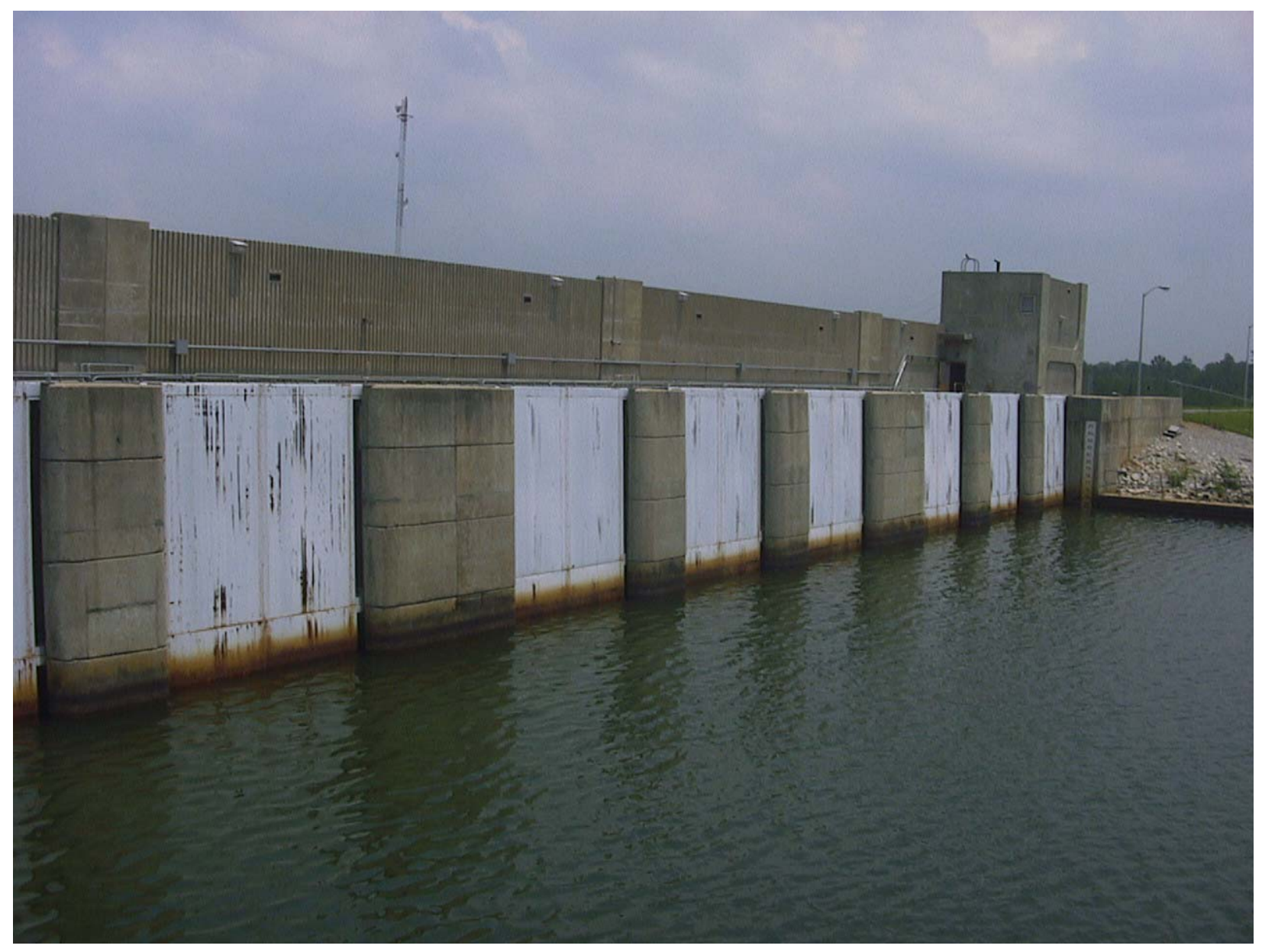

Figure 1-7. Upstream view of the St. Stephen Powerhouse looking from the fish-lift side

\section{Structure Idealization for Seismic Evaluation}

In many cases the seismic analysis can be based on a superstructure-only analytical model. The superstructure-only model assumes that the superstructure acts as a flexible appendage attached to a rigid substructure. When subjected to earthquake ground motions, the substructure, since it is considered to be rigid, moves in unison with the ground; and the accelerations at the top of the substructure are equal to the accelerations at the substructure-foundation interface. The flexible superstructure appendage is therefore assumed to respond as if it were resting directly on the ground. Although not completely rigid, the fundamental mode of vibration for the substructure is usually less than $0.05 \mathrm{sec}$. 


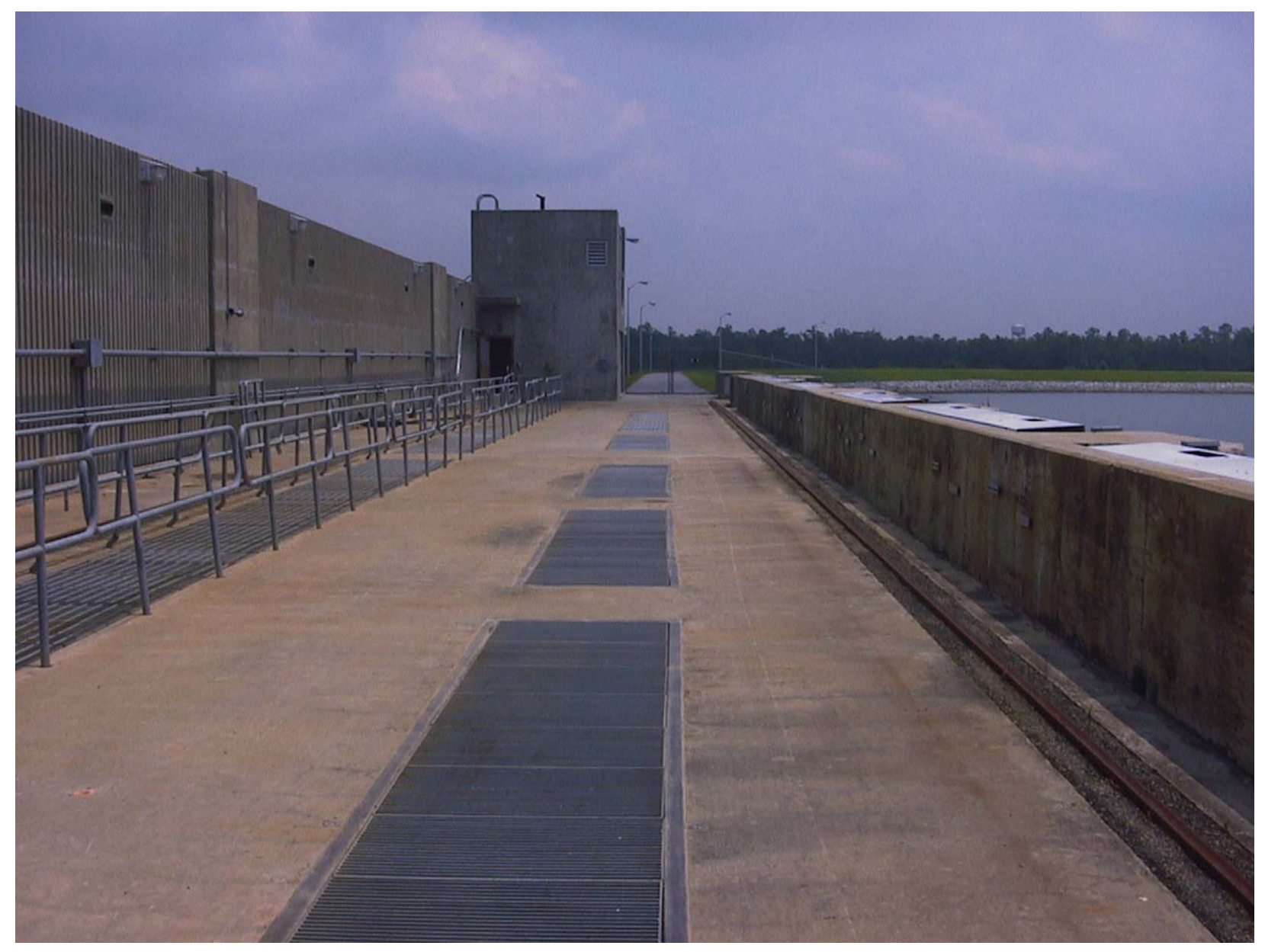

Figure 1-8. Upstream view of the intake deck looking from the fish-lift side

The rigid substructure/flexible superstructure assumption is expected to provide reasonable estimates of the earthquake demands for the superstructure members provided the periods of vibration for the modes contributing to superstructure response are significantly longer than the fundamental period of the substructure. Magnification effects can be significant when any of the superstructure contributing modes have periods of vibration less than twice that of the fundamental mode of the substructure. The superstructure of the St. Stephen Powerhouse is considered to be that part of the upstream wall and roof system above the intake deck (above el 86.0) on the upstream side, and that part of the downstream wall, attached structures, and roof system above the tailrace deck (above el 57.0) on the downstream side. The short, stiff upstream wall above el 86.0 makes the superstructure vulnerable to force and displacement demand magnification effects. Therefore, a finite element analytical model including the substructure was necessary to obtain 
reasonable estimates of force and displacement demands on vulnerable superstructure components, i.e., walls.

Usually the roof support bearings permit free rotation at each end of the roof system. However, free translation is confined to one end only, and the extent of translation is limited by keepers or slotted plates to that required for temperature expansion and contraction. The assumptions made with respect to the boundary conditions at each end of the roof span are critical to the analysis for walls. If the earthquake displacement demands on the wall exceed the free translation capacity of the bearings, the stiffer wall will begin to carry some of the inertial force due to the more flexible wall mass. In such circumstances an analytical model of the entire roof-wall superstructure system is required. Both "fixed against translation" and "free to translate" boundary conditions must be investigated to obtain maximum earthquake demands on each powerhouse superstructure wall.

Field investigations indicate that the T-beams for the high roof are fixed at the upstream wall (shim plates welded to embedded wall plate using 3/16-in. fillet welds), and free at the downstream wall (T-beam bearing plate resting on Neoprene pad, bolt through plate with slotted holes in plate). Figures 1-9 and 1-10 show the upstream and downstream support conditions, respectively, and the available embedded-plate widths supporting the T-beam. Because the bearings are not ideally fixed or free, and because earthquake displacement demands are expected to exceed the free translation capacity of the expansion end bearings, two separate conditions are explored to determine the potential influence on force and displacement demands. The first condition, identified as the ideal condition, assumes the bearings will perform as intended with the bearings at the upstream wall fixed against translation and the bearings on the downstream wall free to translate (Figure 1-10). For the ideal condition the entire roof mass will be attracted by the fixed support on the short upstream wall. This can be modeled by eliminating translation restraint for the T-beams at the free bearing supports (on top of downstream wall). The second condition, identified as the nonideal condition, assumes that the free bearing has reached its translation limit and both walls will attract inertial forces in proportion to their lateral stiffness. Modeling for this condition can be accomplished by preventing joint restraints at each end of the T-beams. The condition providing the greatest force and displacement demands (ideal condition for upstream wall, nonideal condition for downstream wall) are used for final assessments. 


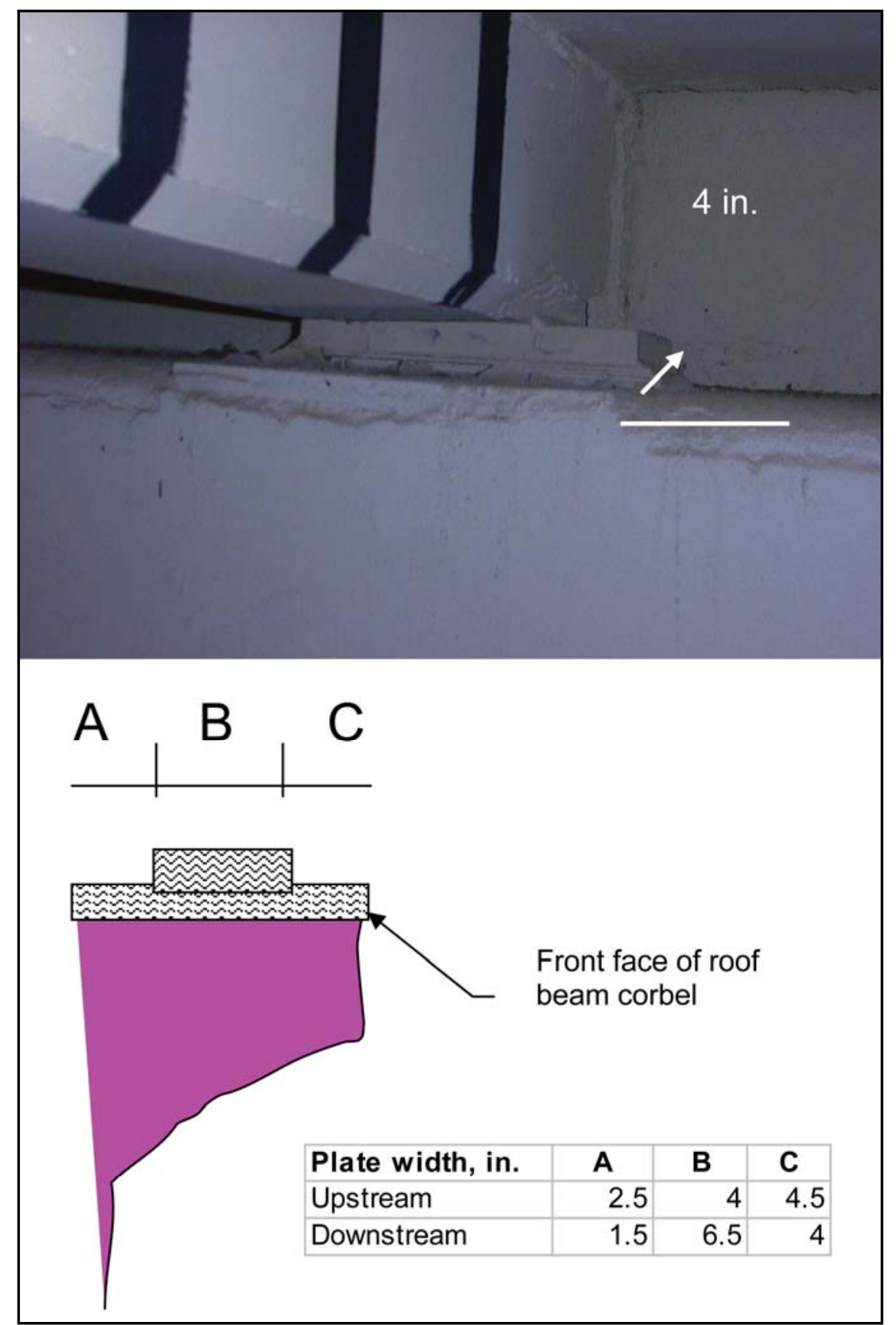

Figure 1-9. Upstream T-beam connection: shim plates welded to embedded wall (an ideal hinge condition)

The capacity of the fixed bearings to resist lateral load will be limited by the fillet weld strength. The shear resistance of a fillet weld is calculated by Equation 1-1:

$$
R_{n}=\phi F_{w} A_{w}
$$




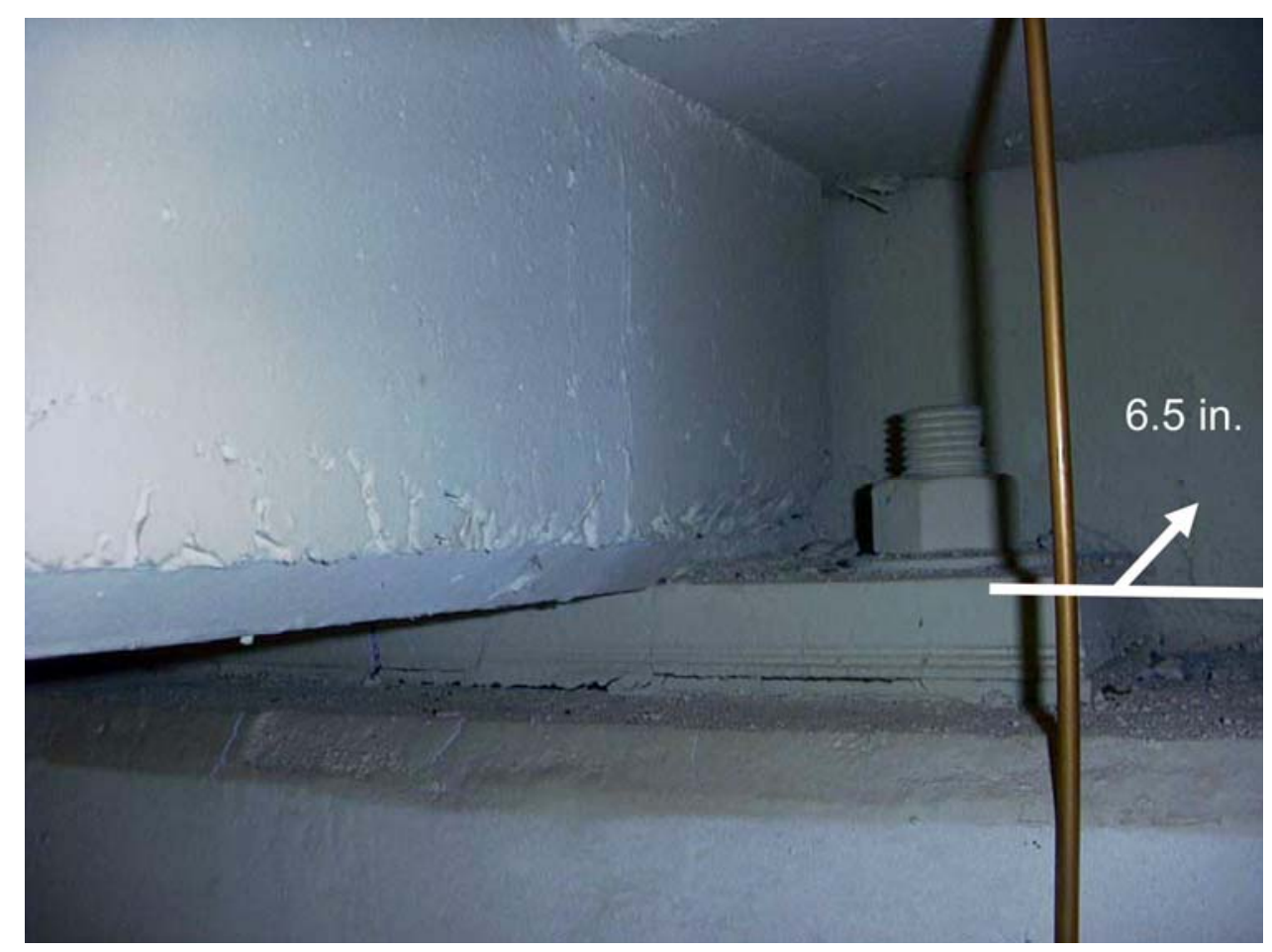

Figure 1-10. Downstream T-beam connection: T-beam bearing plate rests on Neoprene pad, bolt through plate with slotted holes (an ideal roller condition). Note: The slot is assumed to permit less than $1 \mathrm{in.} \mathrm{of} \mathrm{free} \mathrm{travel} \mathrm{in} \mathrm{each} \mathrm{direction.} \mathrm{The} \mathrm{free} \mathrm{travel} \mathrm{length} \mathrm{is} \mathrm{estimated} \mathrm{on}$ the assumption that the washer shown in the figure completely conceals the slot.

where

$$
\begin{aligned}
R_{n}= & 0.75(42) 0.13=4 \mathrm{kips} / \mathrm{in} . \\
\phi= & \text { resistance factor, o.75 (per Table J2.5, American Institute of } \\
& \text { Steel Construction (AISC) 1994) } \\
F_{w}= & 0.60 F_{E X X}=0.60(70)=42 \mathrm{ksi}(\text { per Table J2.5 AISC) } \\
A_{w}= & \text { effective area of weld }=0.707(0.1875)=0.13 \mathrm{in} .^{2} / \mathrm{in} .
\end{aligned}
$$

Assume the weld length per bearing $=2$ sides $\times 6.5$ in. $-4 \times 0.5$ in. $=$ 11.0 in.

Based on these assumptions the fixed bearings would have a capacity to resist $11 \times 2 \times 4=88 \mathrm{kips}$ per T-beam or $11 \mathrm{kips}$ per foot. It should be noted that there are two stems per beam and therefore two connections per beam. 


\section{System mass}

Earthquake force and displacement demands are functions of system mass. Therefore the masses of all structural and nonstructural components are needed for the development of a reliable analytical model.

Mass attributed to the nonstructural roofing needs to be included. For the powerhouse, roofing consists of an elastomeric membrane with 2 in. of gravel ballast. A roofing weight of $40 \mathrm{psf}$ for the superimposed dead (10 psf) and live loads (30 psf) was used for the design. Roof live load was not considered in the seismic evaluation since roof live load would not likely be present during an earthquake event.

The mass of the structural elements must also be estimated accurately to achieve reasonable estimates of force and displacement demand. Those wall sections that are continuous from roof to supporting floor (without door openings) will be required to carry the inertial forces generated by the mass above door openings. Assuming a $1-\mathrm{ft}$ section of wall is analyzed, the effect of this additional mass can be estimated by multiplying the mass of the 1 - $\mathrm{ft}$ section by the ratio of total wall length (including openings) to the total length of continuous wall sections. For the St. Stephen Powerhouse a 10 percent increase in mass for the continuous walls seems reasonable since the extent of door openings is small.

As stated previously the mass of the overhead crane is also important to the analysis. It is assumed for the analysis that the overhead crane is positioned in the erection bay. The total weight of the 135/20-ton crane is $152,200 \mathrm{lb}$. The crane weight is equally distributed to the upstream and downstream walls, with 50 percent assigned to the upstream wall and 50 percent assigned to the downstream wall. For the erection bay this will result in a weight per foot of wall (for both the upstream and downstream walls) equal to

$$
\frac{0.5(152.2)(1.10)}{66.0}=1.27 \mathrm{kips} / \text { foot }
$$

A uniform lengthwise distribution along the entire erection bay is acceptable since as yielding takes place at one wall location, the inertial forces will quickly distribute to other nonyielding wall sections. This process will occur well before collapse. The crane mass is included in both the "ideal" and "nonideal" bearing boundary condition models described 
above. The crane mass will increase force and displacement demands and periods of vibration.

\section{Material properties}

From the drawings it was determined that the design compressive strength for the concrete was 3,000 psi for the superstructure and 2,500 psi for the substructure mass concrete. Grade 40 steel (yield strength equal to $40,000 \mathrm{psi}$ ) was used for the reinforcement of structural concrete as well for control of cracking caused by temperature and shrinkage.

The actual concrete compressive strength used for seismic evaluation purposes will be higher than the design compressive strength. Practice is to use an actual compressive strength equal to 150 percent of the design compressive strength. The 50 percent increase accounts for long-term strength gain (above the 28-day design strength), and accounts for the probable strength being greater than design strength. Concrete shear strength, cracking moment capacity, and modulus of elasticity are calculated based on the actual compressive strength.

The modulus of elasticity for both structural and mass concrete is approximated by Equation 1-3:

$$
E_{c}=33 w \sqrt{w f_{c a}^{\prime}}
$$

where

$$
\begin{aligned}
w= & \text { weight of concrete in pcf (can be assumed as equal to 150 pcf) } \\
f_{c a}^{\prime}= & \text { actual strength of concrete (1.5 times the specified 28-day } \\
& \text { design compressive strength) }
\end{aligned}
$$

Based on Equation 1-3, the modulus of elasticity for the concrete based on actual strength is estimated to be $555,408 \mathrm{ksf}$.

Yielding is expected to occur in the superstructure walls. The effective moment of inertia $I_{E}$ of reinforced concrete members at near yield conditions can be significantly less than that represented by the gross section moment of inertia $I_{G}$. For powerhouse superstructure walls, the effective moment of inertia should be calculated and used in the response spectrum analyses to assure that the response of the powerhouse 
superstructure to earthquake ground motions is reasonable. The effective moment of inertia is an average value for the entire member and considers the distribution of cracking along the member length. The effective moment of inertia of reinforced concrete structures can be estimated based on the relationship between the cracking moment (i.e., the moment required to initiate cracking while ignoring the reinforcing steel) and the nominal moment capacity of the reinforced concrete wall section. The nominal moment capacity is the moment capacity of the cracked section calculated in accordance with provisions and assumptions of the American Concrete Institute (ACI) 318 strength design method before the application of any strength reduction factors. In the ACI strength design method it is assumed that strains are linear across the section. The nominal moment capacity for pure bending assumes that the ultimate capacity of the concrete in compression (compressive stress block) is equal in magnitude and opposite in direction to the ultimate (yield) capacity of the reinforcing steel. The concrete ultimate compressive force and steel ultimate tensile force create a couple that provides the nominal moment capacity for the section. The nominal moments and cracking moments used to estimate effective moment of inertia are for those regions where moments are at their maximums. For powerhouse walls this can be at the base of cantilever wall members or in upper wall sections where an abrupt change in wall thickness occurs. Once the cracking moment $M_{C R}$ (moment required to crack a structural concrete member assuming no contribution from the reinforcement, and assuming a modulus of rupture of $7.5 \sqrt{f_{c}^{\prime}}$ ) and the nominal moment capacity $M_{N}$ have been determined, the ratio of the effective stiffness $I_{E}$ to the gross stiffness $I_{G}$ can be estimated as follows:

$$
\frac{I_{E}}{I_{G}}=0.8-0.9\left[\frac{M_{N}}{M_{C R}}-1\right] \text { Must be } \geq 0.35 \text { and } \leq 0.80
$$

where

$$
\begin{aligned}
I_{G} & =\text { gross section moment of inertia } \\
I_{E} & =\text { effective moment of inertia } \\
M_{N} & =\text { nominal moment capacity } \\
M_{C R} & =\text { cracking moment capacity }
\end{aligned}
$$




\section{Sectional properties for the erection bay wall elements}

The following material properties have been determined for the erection bay walls assuming that the walls will have earthquake moment demands in excess of moment capacity, i.e., yielding occurs:

- Cracking moment capacity

- Nominal moment capacity

- Ratio of effective moment of inertia to gross moment of inertia IE/IG

These sectional properties are summarized in Table 1-1 based on actual compressive strength conditions. For the initial SAP2000 analysis all the members not listed in Tables 1-1 or 1-2 will be assigned an effective stiffness equal to 0.8 times the gross stiffness $\left(E I_{E}=0.8 E I_{G}\right)$. The use of a maximum effective stiffness equal to 80 percent of the gross section stiffness assumes that some cracking and slight degradation in stiffness will occur under cyclic earthquake loading. The 20 percent minimum reduction in stiffness is per recommendations by M. J. N. Priestley (Strom and Ebeling 2005). Since the period of vibration is equal to the square root of the mass divided by the stiffness, it can be concluded that a 20 percent reduction in stiffness will provide earthquake demands that vary only slightly from those obtained from analyses based on gross section properties. The precast prestressed concrete T-beams should not crack during an earthquake. Therefore for those members the gross section properties described in Table 1-2 can be used in the analysis. The nominal moment capacities are based on the ultimate capacity of the concrete at a maximum strain of 0.002 , and on the yield strength of the steel assuming an ultimate strain capacity of 5 percent. By limiting the compressive strain in the concrete to 0.002, the opportunity for compressive microcracking, which can lead to bond deterioration and eventually to rebar splice failure in plastic hinge regions, is prevented.

Table 1-1. Sectional properties for wall elements $f_{c a}{ }^{\prime}=4,500$ psi (Actual compressive strength).

\begin{tabular}{|l|r|r|r||}
\hline Wall Thickness, $\mathrm{ft}$ & \multicolumn{2}{|l|}{$M_{N}, \mathrm{ft}-$ kips } & \multicolumn{1}{|l|}{ ICR, $\mathrm{ft}-\mathrm{kips}_{\mathrm{E} / \mathrm{I}_{G}}$} \\
\hline 1.0 & 17.23 & 12.83 & 0.49 \\
\hline 1.5 & 32.78 & 30.04 & 0.72 \\
\hline 3.5 & 161.60 & 169.60 & 0.80 \\
\hline 4.5 & 225.20 & 278.30 & 0.80 \\
\hline
\end{tabular}


The properties for the T-beams as described in Table 1-2 are used for the analysis. The mass of the T-beams can be uniformly distributed along the T-beam length, or can be modeled as a series of lumped masses.

Table 1-2. T-Beam properties.

\begin{tabular}{||l|l|l|l|l||}
\hline Beam Type & $\begin{array}{l}\text { Area } A, \\
\text { in.2 }\end{array}$ & $\begin{array}{l}\text { Moment of Inertia I, } \\
\text { in. }\end{array}$ & $\begin{array}{l}\text { Modulus of Elasticity } E, \\
\text { ksi }\end{array}$ & $\begin{array}{l}\text { Weight, } \\
\text { kips/ft }\end{array}$ \\
\hline $\begin{array}{l}\text { 32-in. single T (high } \\
\text { roof) }\end{array}$ & 538 & 49,329 & 4,287 & 0.560 \\
\hline $\begin{array}{l}\text { 16-in. double T (low } \\
\text { roof) }\end{array}$ & 325 & 6,634 & 4,287 & 0.339 \\
\hline
\end{tabular}

Note: T-beam properties are for an 8.0-ft-wide section. 


\section{Performance-Based Evaluation}

A performance-based approach is used to determine if the St. Stephen powerhouse erection bay will meet collapse prevention performance objectives when subject to maximum considered earthquake (2,475-year event), and MCE ground motion demands. The procedure requires computation of displacement and displacement ductility demands for vulnerable powerhouse members, i.e., superstructure walls.

Performance objectives are met if

- Brittle modes of failure are suppressed to allow flexural yielding to take place in the superstructure walls.

- Member displacement ductility capacity exceeds displacement ductility demands.

Detailed discussions on the performance-based seismic analysis and its applications in seismic assessment for building structures are available in Medhekar and Kennedy (2000), Chandler and Mendis (2000), and Moehle (1992).

\section{Procedures Used to Assess Structure Displacement Demand}

An LDP analysis for the St. Stephen powerhouse will be used to assess seismic performance. The LDP uses a response spectrum analysis to determine force and displacement demands on the structure. The LDP is described in detail in FEMA 356, "Prestandard and Commentary for the Seismic Rehabilitation of Buildings" (FEMA 2000). The desired performance level for this evaluation is "collapse prevention." Collapse prevention permits yielding to occur, provided such yielding does not lead to collapse of the structure. Displacements less than those causing collapse are required as illustrated in Figure 2-1. 


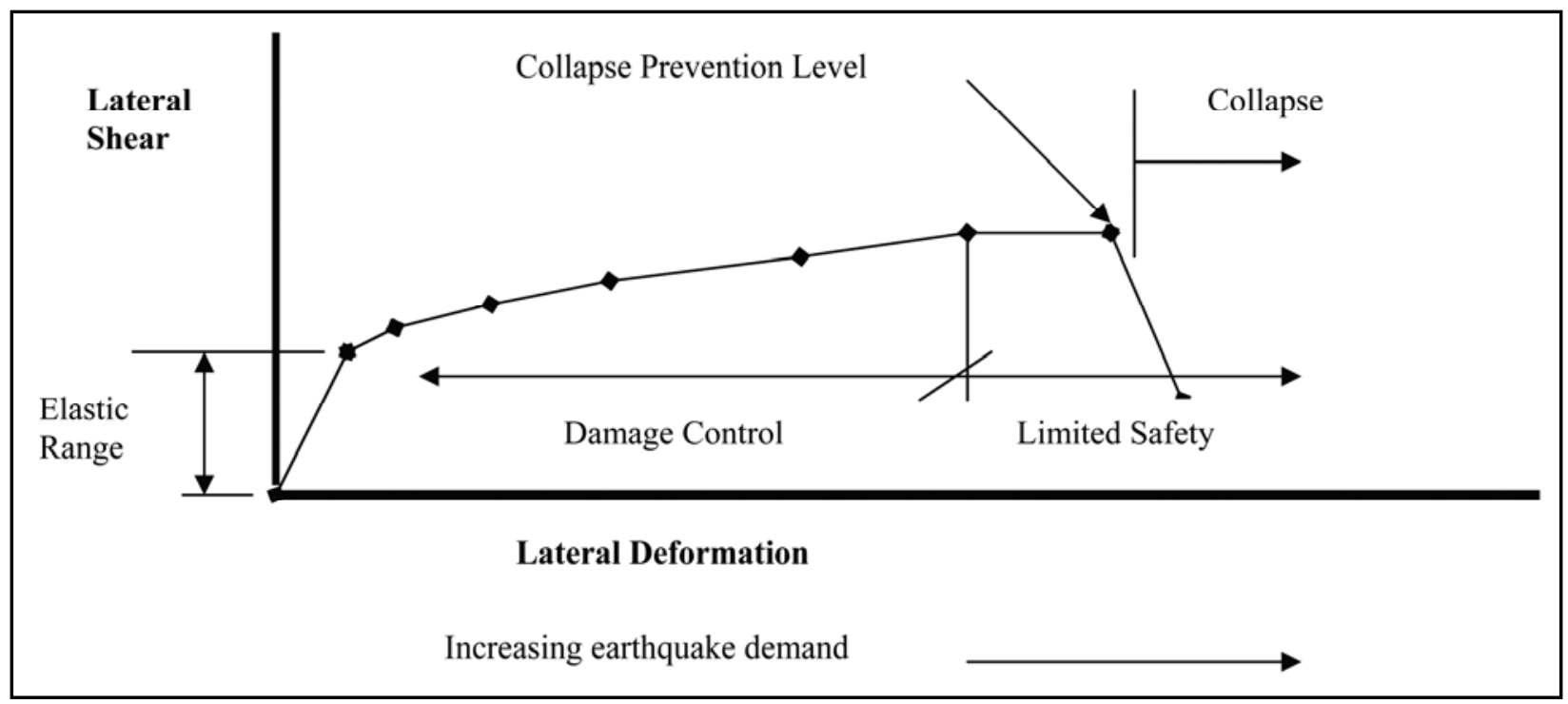

Figure 2-1. Performance and structural deformation demand for ductile structures.

\section{Earthquake Demands on Inelastic Systems}

An LDP, i.e., response spectrum analysis, is a linear elastic analysis that provides force and displacement demands assuming the structure remains elastic during the design earthquake. The inelastic response of a structure subjected to earthquake ground motion is different from the elastic response, however, because the vibrational characteristics of the structure change as the structure yields. The predominant change is a shift in the fundamental period of vibration. In most cases, a reduction in earthquake demand occurs as the period of the structure lengthens. In Figure 2-2, a capacity spectrum is used to illustrate the inertial force reduction (or spectral acceleration reduction) that occurs when a structure yields. In Figure 2-2, earthquake demands for an elastic system, as represented by a response spectrum, are reconciled with the elastoplastic load/displacement characteristics for a ductile structure. Point $A$ represents the earthquake demand assuming the structure remains elastic, with the line $O A$ representing the linear elastic response. Point $B$ represents the earthquake demands for elastoplastic behavior with the line $O B C$ representing the load/displacement characteristics of the elastoplastic system.

As can be seen, the earthquake demand on the elastoplastic system is substantially less than that of the elastic system. However, when the fundamental period of the structure falls in the ascending portion of the response spectrum, a shift in period may actually increase earthquake 
demands. This can occur for stiff structures founded on soft soils. It should also be recognized that damping increases significantly as structures yield. This also reduces earthquake demand. Simple techniques have been developed for estimating earthquake demands on inelastic systems. For structures with fundamental periods of vibration located in the constant acceleration range of the response spectrum, the inelastic response capability will be a function of structure displacement ductility $\mu$, and can be estimated using the equal energy principle. The fundamental period of vibration of the structure is designated as $T$ in this report. For structures with fundamental periods of vibration in the constant velocity range of the response spectrum, the inelastic response capability will also be a function of structure displacement ductility $\mu$, and can be estimated using the equal displacement principle.

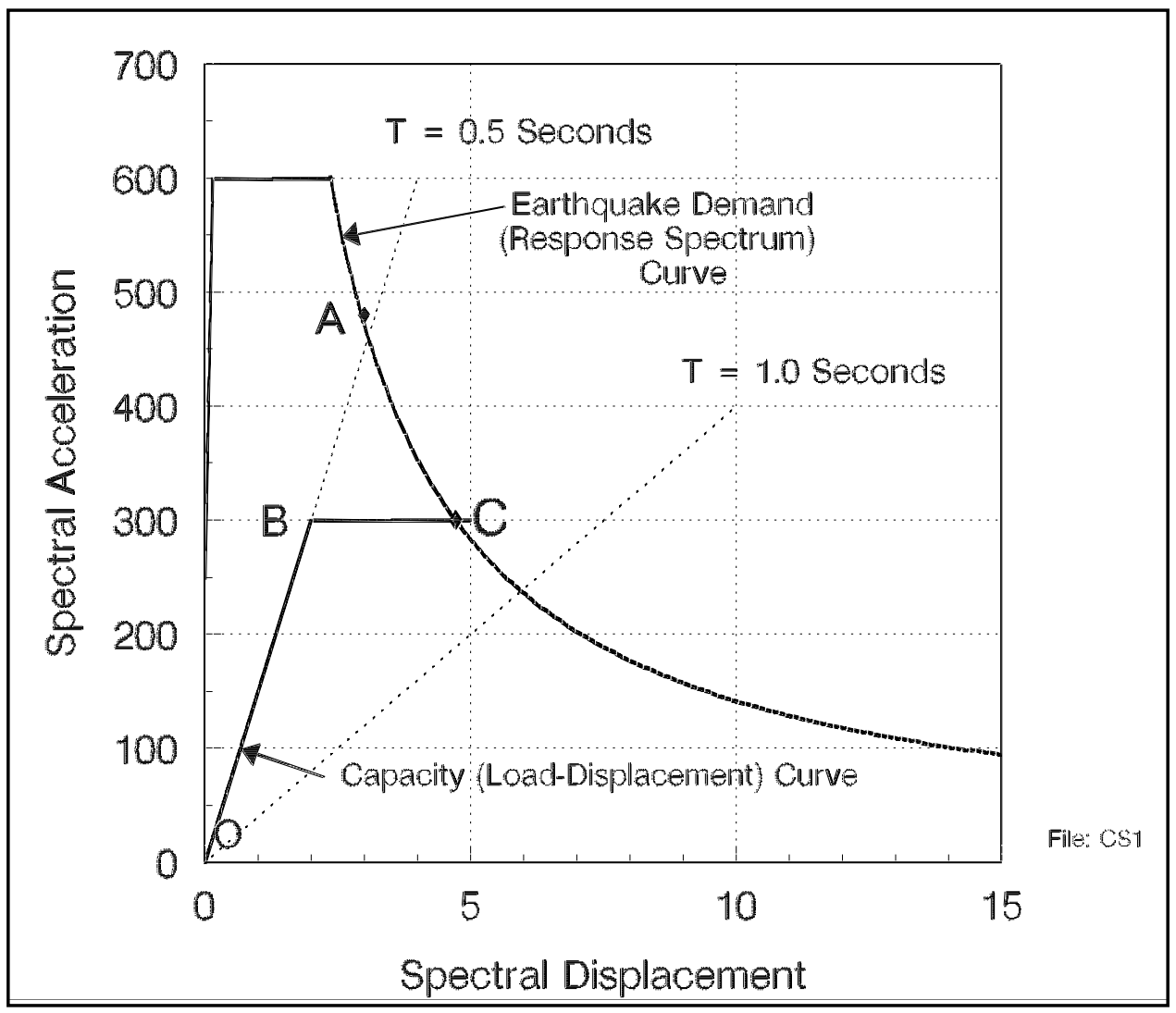

Figure 2-2. Earthquake demands on inelastic structures.

Structures with fundamental periods of vibration less than the characteristic ground motion period will exhibit an equal energy response. The characteristic ground motion period, designated as $T_{o}$ in this report, represents the intersection of the response spectrum constant acceleration range and constant velocity range. The characteristic ground motion 
period generally varies between 0.2 and $0.7 \mathrm{sec}$ depending on site conditions, with firm sites having shorter characteristic periods than soft sites. The characteristic ground motion period is illustrated in Figure 2-3. This figure is a tripartite plot of a given site-specific response spectrum that has been smoothed to provide a straight line (on $\log / \log$ scale) representation of earthquake demands in the constant acceleration, constant velocity, and constant displacement ranges.

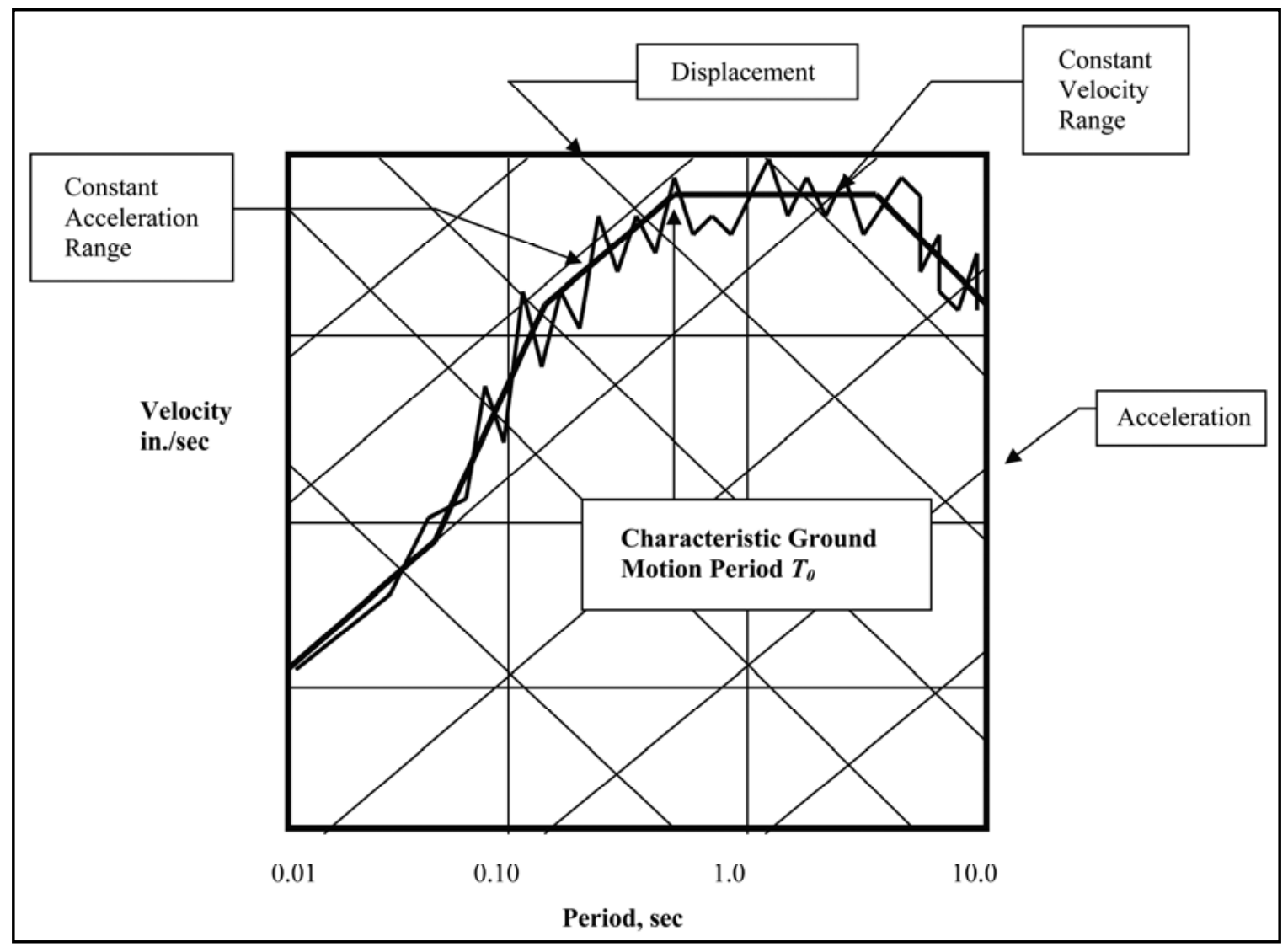

Figure 2-3. Characteristic ground motion.

For an equal energy response, the structure must have sufficient displacement ductility to provide the reserve inelastic energy capacity needed to resist earthquake ground motion demands. The equal energy response concept is presented in Figure 2-4. For a given displacement ductility $\mu_{\delta}$ the inelastic (yield) capacity $F_{Y}$ must be sufficient to produce an equal energy response. Equating the energy for a linear elastic response to that for an inelastic response (hatched area under the nonlinear portion of the load displacement curve equal to the hatched area under the linear elastic curve), it can be determined that the yield capacity of the structure 
must be equal to or greater than the capacity required of the structure if it were to remain elastic $F_{E}$ divided by $\sqrt{2 \mu_{\delta}-1}$, or:

$$
F_{Y}=\frac{F_{E}}{\sqrt{2 \mu_{\delta}-1}}
$$

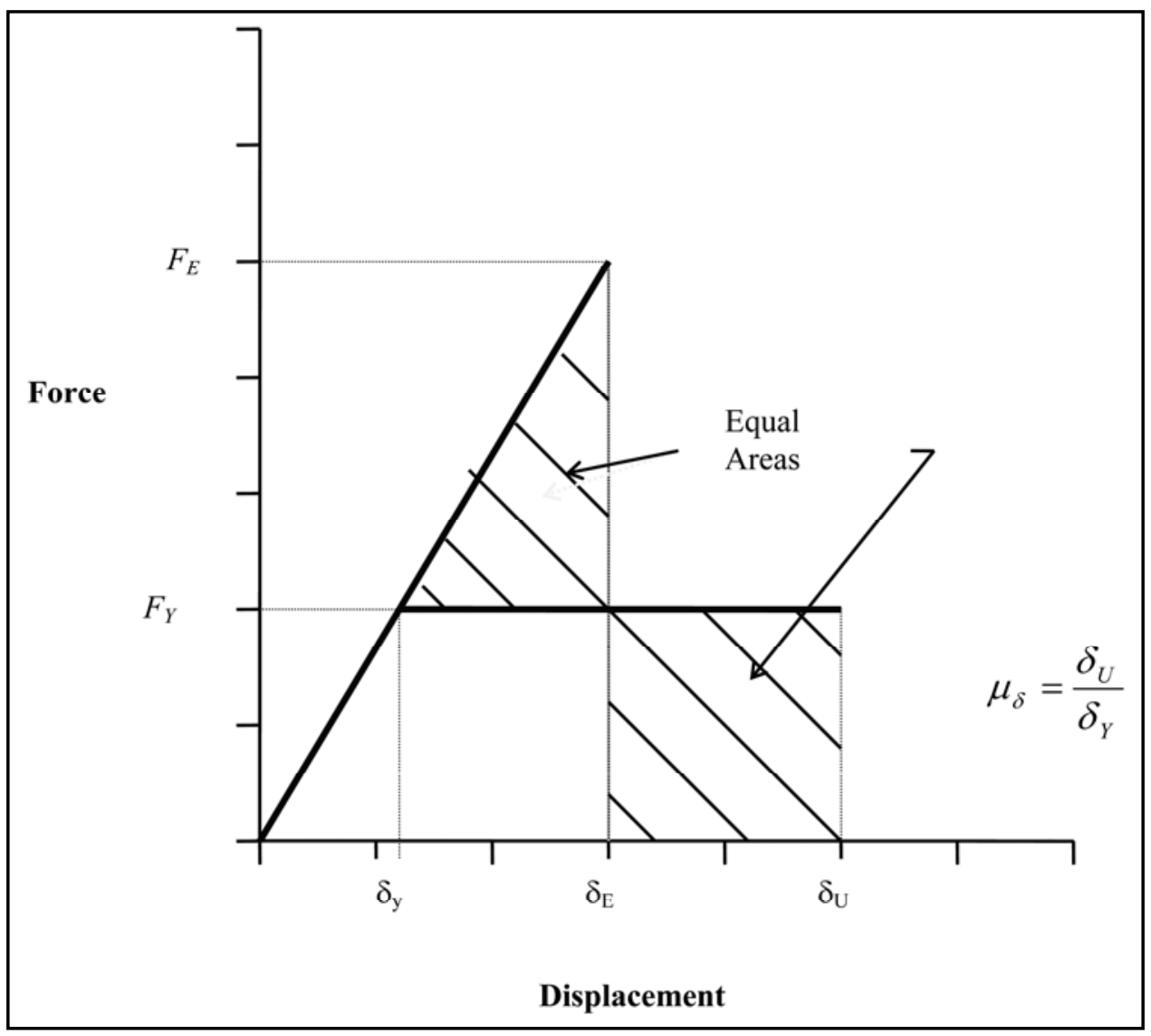

Figure 2-4. Equal energy response.

It can also be seen that the displacement capacity of the inelastic structure must be larger than the displacement of the elastic structure if the structure is to survive.

Structures with fundamental periods of vibration greater than the characteristic ground motion period will exhibit an equal displacement response. An equal displacement response means that if the structure is to perform as intended, the displacement ductility capacity must be sufficient to provide a structure displacement capacity equal to or greater than the peak displacement the structure will experience during the design earthquake. The equal displacement response concept is presented in 
Figure 2-5. From Figure 2-5 it can be determined that the yield capacity of the structure must be equal to or greater than the capacity required of the structure if it were to remain elastic $F_{E}$ divided by $\mu_{\delta}$, or

$$
F_{Y}=\frac{F_{E}}{\mu_{\delta}}
$$

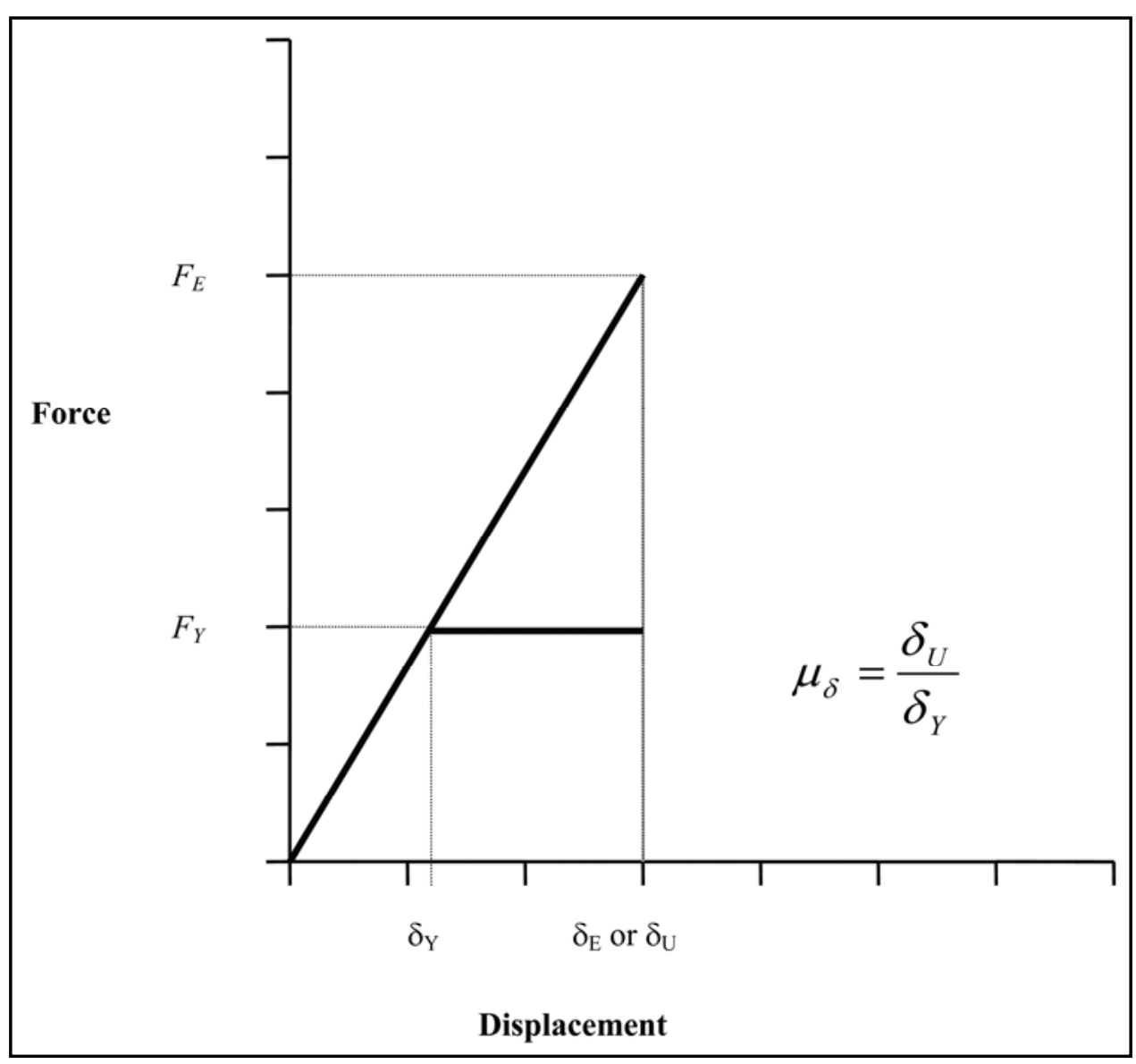

Figure 2-5. Equal displacement response.

It can also be seen that the displacement of the inelastic structure equals that of the elastic structure.

A general relationship has been developed (Paulay and Priestley 1992) for relating required yield strength to elastic demand. This relationship provides a smooth transition from an equal acceleration response $\left(F_{E} / F_{Y}=1\right.$, regardless of $\left.\mu_{\delta}\right)$ at $T=0$, through the equal energy approximation 


$$
\frac{F_{E}}{F_{Y}}=\sqrt{2 \mu_{\delta}-1}
$$

at about $T=0.75 T_{0}$, to the equal displacement approximation $\left(F_{E} / F_{Y}=\mu_{\delta}\right)$ for $T \geq 1.5 T_{0}$. The relationship for the smooth transition is

$$
\frac{F_{E}}{F_{Y}}=1+\frac{\left(\mu_{\delta}-1\right) T}{1.5 T_{0}} \geq \mu_{\delta}
$$

A form of this equation was used to determine the flexural displacement ductility demand $\mu_{\delta}$ on the St. Stephen erection bay walls. The equation is designated in the calculations as the Priestley equation. Since flexural demands are the quantities of interest when determining flexural displacement ductility demand, this equation is expressed in terms of the moment demand obtained from a linear elastic response spectrum (modal) analysis $M_{D E}$ and the yield or nominal moment capacity of the particular member under investigation $M_{N}$. Therefore for a flexural response, the relationship for the smooth transition is in terms of the displacement ductility demand $\mu_{\delta}$ is

$$
\mu_{\delta}=1.5\left(\frac{M_{D E}}{M_{N}}-1\right) \frac{T_{o}}{T}+1 \geq \frac{M_{D E}}{M_{N}}
$$

Equation 2-4 was used to estimate the displacement ductility demands on critical structural elements of the St. Stephen Powerhouse erection bay.

\section{Ductility Capacity of Reinforced Concrete Structures}

Performance evaluations require displacement-based analyses to determine if member flexural displacement ductility capacities are greater than flexural displacement ductility demands. Flexural displacement ductility capacity is related to curvature capacity, plastic hinge length (length of zone where yielding occurs), and member length.

The curvature capacity will depend on the maximum amount of strain that can be placed on the concrete and reinforcing steel. To prevent fracturing of the reinforcing steel, the steel strain should be limited to 5 percent. Static load testing produces ultimate strain capacities of 18 percent or more; but due to low cycle fatigue effects, the maximum permitted for earthquake load conditions is 5 percent. The maximum ultimate strain 
capacity of concrete under dynamic loadings is approximately 0.4 percent. However, when there is inadequate confinement steel, the maximum ultimate strain capacity should be limited to 0.2 percent to prevent compressive microcracking of the concrete that can lead to bond strength deterioration and to subsequent rebar splice failure. Using this strain limit information, the ultimate curvature capacity of a reinforced concrete section can be determined (Figure 2-6).

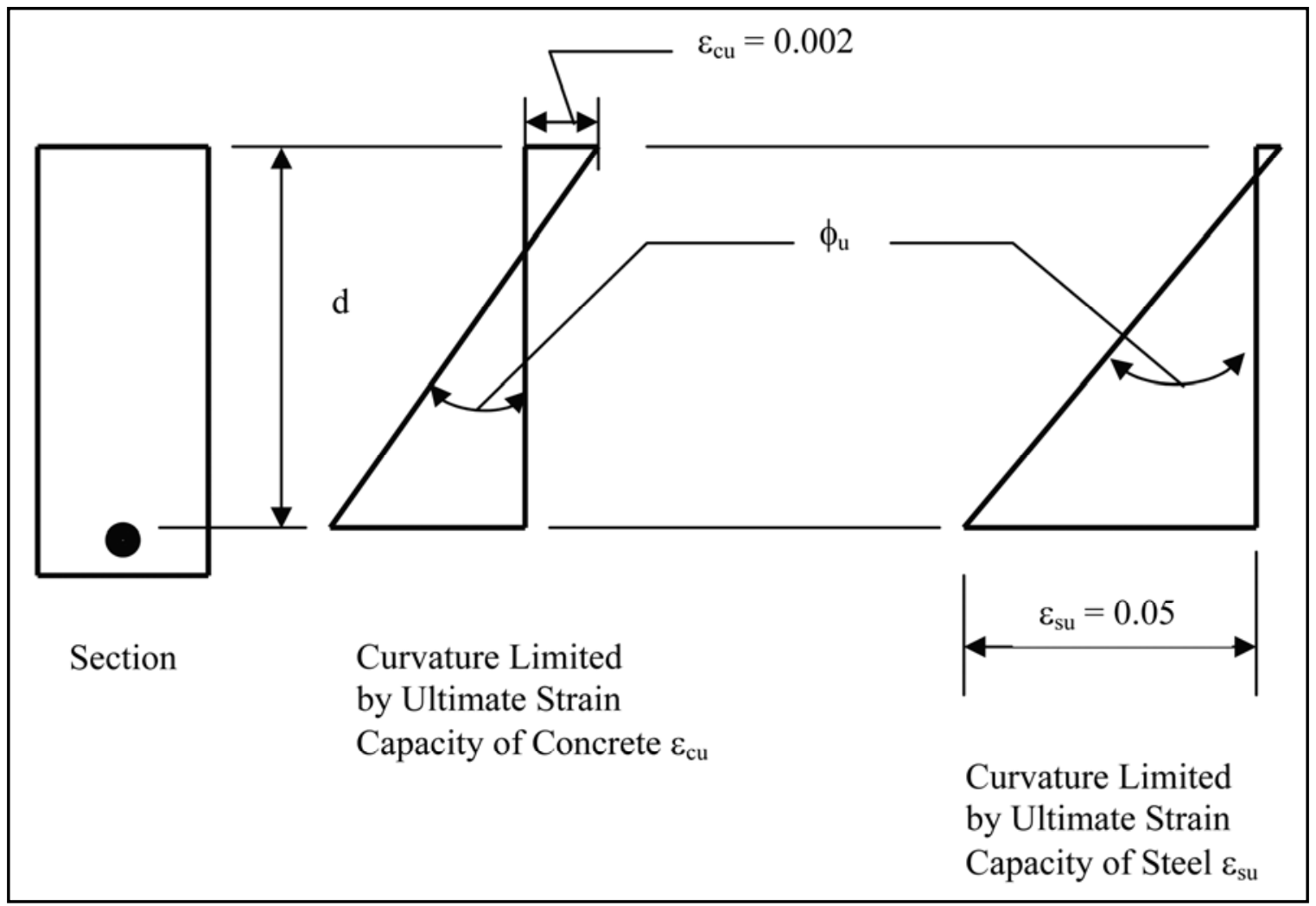

Figure 2-6. Ultimate curvature capacity.

Ultimate rotation capacity is equal to the ultimate curvature capacity times the plastic hinge length. When the nominal moment capacity $M_{N}$ is less than 1.2 times the cracking moment $M_{C R}$, the plastic hinge length to be used in calculating rotational capacity is

$$
\begin{gathered}
I_{p}=0.0435 f_{y}\left(d_{b}\right) \text { (MPa units) } \\
\left\{I_{p}=0.30 f_{y}\left(d_{b}\right)\right\} \text { (ksi units), where: }
\end{gathered}
$$

$f_{y}=$ yield strength of the reinforcing steel

$d_{b}=$ diameter of reinforcing steel 
When the nominal moment $M_{N}$ is greater than twice the cracking moment $M_{C R}$, the plastic hinge length to be used in calculating rotational capacity is

$$
\begin{gathered}
I_{p}=0.08 L+0.0218 f_{y}\left(d_{b}\right) \mathrm{mm} \text { (MPa units) } \\
I_{p}=0.08 L+0.15 f_{y}\left(d_{b}\right) \text { in. (ksi units) }
\end{gathered}
$$

where $L$ is the length of the member.

For nominal moment strengths between $1.2 M_{C R}$ and 2.oM $M_{C R}$ the plastic hinge length can be determined by linear interpolation between the results obtained from the two plastic hinge length equations. The ultimate rotational capacity $\theta_{u}$ of the member can be estimated as follows:

$$
\theta_{u}=\phi_{u}\left(I_{p}\right)
$$

where $\phi_{u}$ is the ultimate curvature capacity.

For cantilevered structures such as powerhouse walls it is advantageous to determine ultimate displacement ductility capacities and compare those with the displacement ductility demands obtained from a seismic analysis.

The displacement ductility capacity of powerhouse superstructure walls and other members that behave as cantilever structures can be determined using various cantilever beam models. For structures where the mass can be assumed to occur at the top of the structure (concentrated mass model) Figure 2-7 applies. This model was used to evaluate the displacement ductility capacity of the St. Stephen powerhouse walls.

For the concentrated mass model (Figure 2-7) the ultimate displacement capacity $\delta_{u}$ can be estimated by

$$
\delta_{\mu}=\frac{\phi_{y} I^{2}}{3}+\left(\phi_{\mu}-\phi_{y}\right) I_{p}\left(I-\frac{I_{p}}{2}\right)
$$

Or the ultimate displacement ductility capacity can be estimated by:

$$
\mu=1+3\left(\frac{\phi_{u}}{\phi_{y}}-1\right) \frac{I_{p}}{l}\left(1-0.5 \frac{I_{p}}{l}\right)
$$




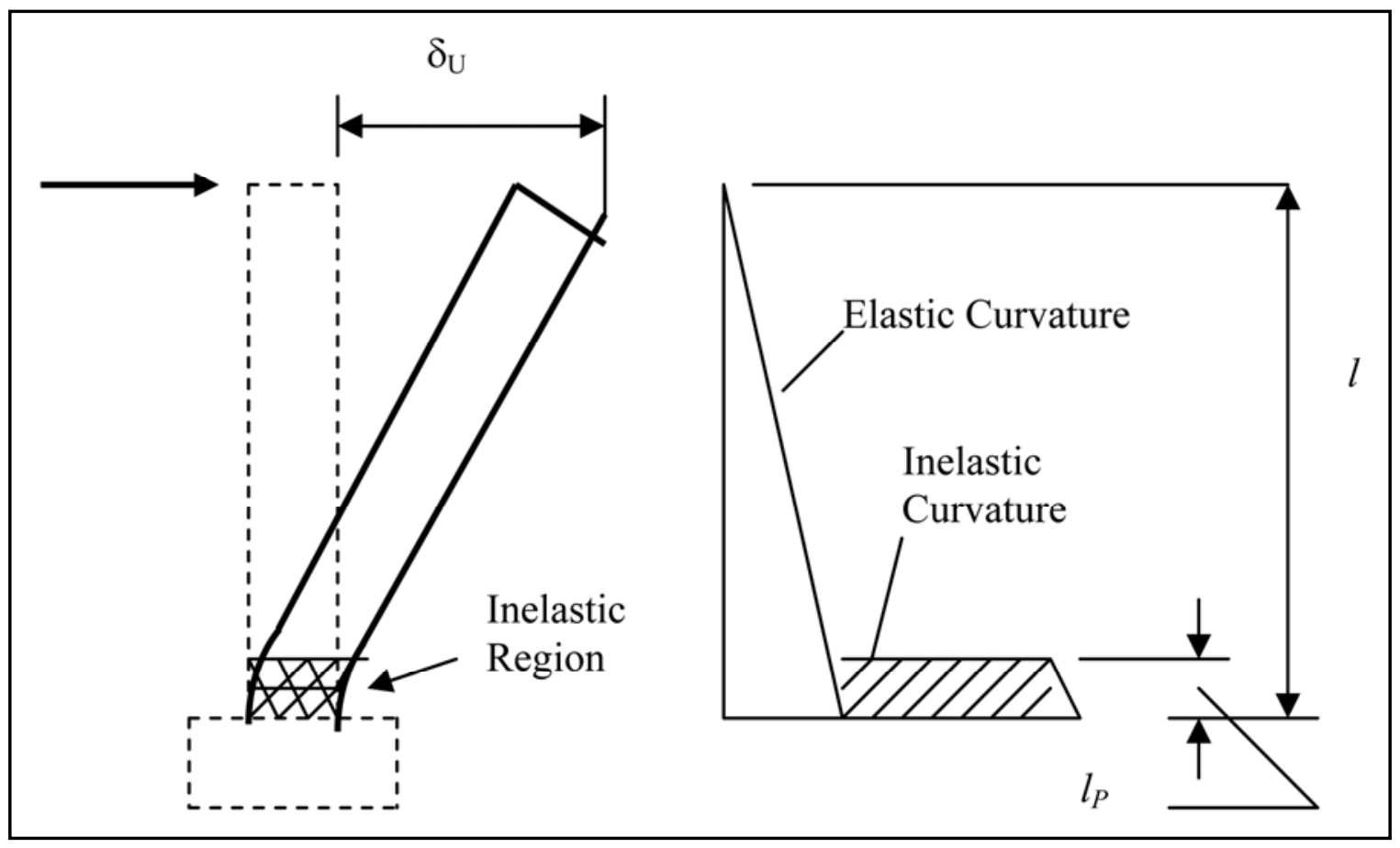

Figure 2-7. Concentrated mass model.

where

$$
\begin{aligned}
\phi_{\mathrm{y}} & =\text { curvature at first yield of the reinforcing steel } \\
l & =\text { length of cantilever }
\end{aligned}
$$

Equations 2-8 and 2-9 were used to assess the displacement capacity and displacement ductility capacity of the St. Stephen erection bay walls.

\section{Moment-Curvature (M-Phi) Analysis}

The maximum curvature capacity is needed to determine the maximum displacement ductility capacity for critical structural elements of the St. Stephen Powerhouse erection bay. Maximum curvature capacity is based on the strain limits established previously for the concrete and steel, and is dependent on the axial load on the member.

The maximum displacement ductility demand is a function of the nominal moment capacity of the member as indicated by Equation 2-4.

Both the maximum curvature capacity and nominal moment capacity can be determined by moment curvature analysis. Moment curvature analyses for critical structural elements of the St. Stephen Powerhouse erection bay 
were performed using the Corps M-Phi computer program developed by Ehsani and Marine (1994). In a moment curvature analysis, as with most section analyses, the strain is assumed to vary linearly across the cross section of the member. Strain values for concrete and steel are selected. Then, based on known relationships between stress and strain, the forces in the concrete and steel are calculated and resisting moments determined for a particular axial load condition specified for the member. The strain values selected determine the curvature as illustrated in Figure 2-6. This process is repeated until the ultimate strain capacity of either the steel or concrete is reached and until a complete moment-curvature relationship for the member is obtained. The results of the M-Phi analyses for the St. Stephen Powerhouse critical members are illustrated in Figure 2-8. As shown in that figure, there is a reduction in the moment values immediately following cracking of the section. This occurs as the curvature increases. This behavior is common for lightly reinforced sections. As soon as the concrete cracks in tension, the share of the tensile stress carried by the concrete shifts to the steel, resulting in a lower moment. Once cracking occurs and as curvature increases, all the steel eventually reaches strains greater than yield. For lightly reinforced wall sections the steel will reach ultimate strain capacity before the concrete.

\section{Interpreting Analysis Results}

It is expected that flexural yielding will occur in various members of the powerhouse superstructure during major earthquake events. However, for flexural yielding to occur, various brittle modes of failure such as shear must be suppressed. The displacement ductility demand and capacity information previously provided relate to the flexural yielding mode of failure. The location where yielding occurs (plastic hinge regions) can be easily identified, being those locations where elastic moment demands exceed nominal moment capacities. For the MCE $+\sigma$ and the 2,475-year earthquake events, flexural yielding occurred in the powerhouse erection bay superstructure walls at the following locations:

- The uppermost upstream wall (1.5-ft-thick wall supporting the roof Tbeams) connects to the intake deck at el 86 .

- The uppermost downstream wall (1.5-ft-thick wall supporting the roof T-beams) connects to the crane rail corbel at el 81.25.

- The lower section of the downstream wall (3.5-ft-thick wall) attaches to the tailrace deck at el 57 . 


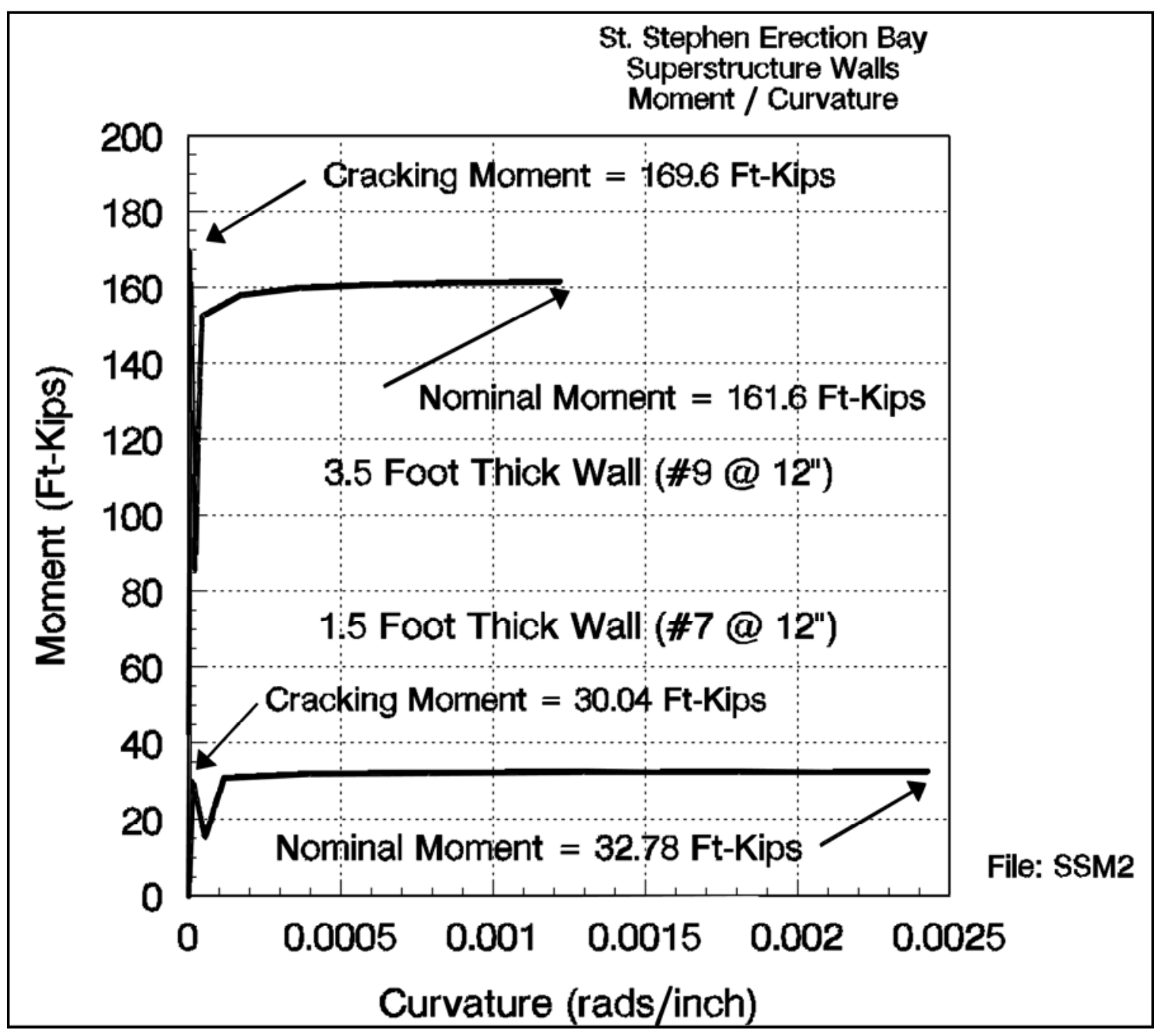

Figure 2-8. Results of M-Phi analyses for St. Stephen erection bay walls.

Failure at any one of these yield regions can lead to collapse of the erection bay roof. However, to determine if collapse might occur during an extreme earthquake event, several brittle modes of failure, in addition to the flexural mode of failure, must also be investigated. The potential for failure is assessed using demand to capacity evaluations. The type of demand to capacity evaluations used to evaluate collapse performance and maximum permissible demand to capacity ratio (DCR) are presented in Table 2-1. 
Table 2-1. Demand to capacity evaluations.

\begin{tabular}{|l|l|l||}
\hline Potential Failure Mechanism & Type of Demand to Capacity Evaluation & Maximum DCR \\
\hline Fracture of reinforcing steel & $\begin{array}{l}\text { Displacement ductility demand to displacement } \\
\text { ductility capacity }\end{array}$ & 1.0 \\
\hline $\begin{array}{l}\text { Crushing and spalling of } \\
\text { concrete }\end{array}$ & $\begin{array}{l}\text { Displacement ductility demand to displacement } \\
\text { ductility capacity }\end{array}$ & 1.0 \\
\hline Failure of rebar splices & $\begin{array}{l}\text { Displacement ductility demand to displacement } \\
\text { ductility capacity }\end{array}$ & 1.0 \\
\hline Shear failure & Elastic shear demand to shear capacity & 1.0 \\
\hline Sliding shear failure & Elastic shear demand to sliding shear capacity & 1.0 \\
\hline
\end{tabular}

As with older structures, the reinforcing steel in the walls of the St. Stephen powerhouse is spliced at the base of the walls. This means the splices are located in potential plastic hinge (yield) regions. Splice failures can occur as damage accumulates in plastic hinge regions. In general some limited flexural yielding can be tolerated in conventionally reinforced structures. But to assure the structure will not collapse due to splice failures, the compressive strain in the concrete confining the splice should not exceed 0.2 percent. Strains below 0.2 percent will prevent microcracking in the concrete, and as such will prevent the onset of bond deterioration, i.e., the splitting of the concrete surrounding the steel, that can lead to splice failure. Crushing of the concrete will not occur until compressive strains in the concrete exceed 0.4 percent. Therefore the 0.2 percent strain limit placed on the concrete to prevent splice failures will also protect against spalling.

Shear failures are brittle sudden failures and therefore are unacceptable. To prevent shear and sliding shear failures, the elastic shear demands from the response spectrum analysis should not exceed the shear or sliding shear capacity of the member (DCR $\leq 1.0)$. Shear and sliding shear capacities are described in the following section.

\section{Shear Capacity}

The capacity of the concrete in shear (diagonal tension) is due to aggregate interlock, to a lesser extent to the shear resistance available from the transverse reinforcing (traditional truss mechanism), and to shear strength enhancement as the result of axial load. The total ultimate shear strength $V_{U}$ can be taken as 


$$
V_{u}=\phi\left(V_{c}+V_{s}\right)=0.85\left(V_{c}+V_{s}\right)
$$

where $V_{C}$ is nominal shear strength provided by concrete and $V_{S}$ is nominal shear strength provided by shear reinforcement.

A conservative representation of the concrete shear strength $V_{C}$ is

$$
V_{c}=\left\{2\left[k+\frac{P}{2000 A_{g}}\right] \sqrt{f_{c}^{\prime}}\left(A_{e}\right)\right\} \text { (psi units) }
$$

where

$$
\begin{aligned}
k= & 1 \text { for } \mu_{\delta}=1, \text { and } k=0.5 \text { for } \mu_{\delta}=2.0, \text { with linear interpolation } \\
& \text { between these values for } 1<\mu_{\delta}<2.0, \text { where } \mu_{\delta}=\text { flexural } \\
& \text { displacement ductility demand } \\
P= & \text { axial load on section } \\
A_{g}= & \text { gross concrete area } \\
A_{e}= & 0.8 A_{g} \\
f_{c}^{\prime}= & \text { actual concrete compressive strength (the actual concrete } \\
& \text { compressive strength, which may be as high as or higher than } \\
& 1.5 \text { times the design compressive strength, should be used } \\
& \text { when calculating the shear capacity) }
\end{aligned}
$$

The relationship between concrete shear strength and flexural displacement ductility is illustrated in Figure 2-9. For the St. Stephen Powerhouse the lowest shear strength (residual shear strength) was used in the DCR analysis since the flexural ductility demands always exceeded 2.

Sliding shear (shear friction) along the base of a structure or structural member should also be investigated. The shear friction shear capacity $V_{S F}$ can be determined by the following expression:

$$
V_{S F}=\mu_{S F}\left(P+0.25 A_{s} f_{y}\right)
$$

where

$$
\begin{aligned}
\mu_{S F} & =\text { sliding shear coefficient of friction, per ACI } 315 \\
P & =\text { axial load on section }
\end{aligned}
$$


$A_{s}=$ area of the longitudinal reinforcing steel across the potential failure plane

$f_{y}=$ yield strength of the reinforcing steel

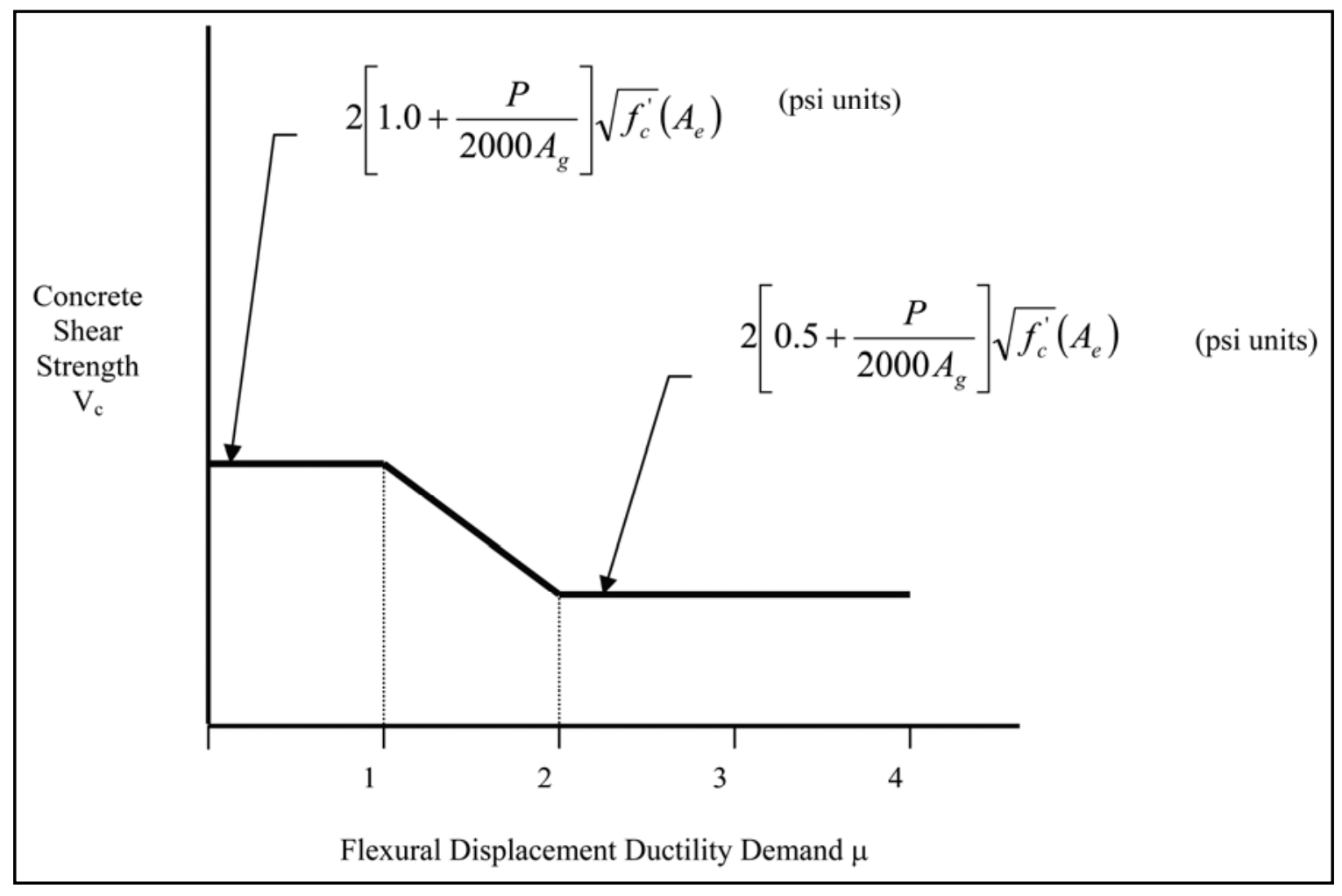

Figure 2-9. Concrete shear strength versus ductility. 


\section{Earthquake Ground Motions}

Earthquake ground motion response spectra representing the probabilistically derived 2,475-, 1,000-, and 475- year events (exposure periods) were developed to represent earthquake demands to be considered for the seismic evaluation of the St. Stephen powerhouse. Deterministically derived MCE mean and mean $+1 \sigma$ (probability of nonexceedance of 84 percent) events were also developed as potential earthquake demands for the seismic evaluation. These design earthquake ground motions were developed for this analysis by a review of the current understanding of the seismic setting and earthquake sources that dominate the seismic hazard for this site. Earthquake demands are provided in terms of acceleration response spectra for site class B conditions. Site class B represents rock with a shear wave velocity between 2,500 and 5,000 fps. Acceleration response spectra ordinates for the aforementioned return periods are presented in Table $3-1$. Since performance evaluation was for collapse prevention, only the 2,475-year event information was used in the probabilistic response spectrum analyses.

The seismic hazard of the project is dominated by and located within the Charleston seismic zone. A source zone is specified to quantify the recognized seismic hazard because the central and eastern North American geologic setting and current data do not allow specifying definitive locations of causal fault sources. The Charleston seismic zone maximum earthquake hazard is based predominantly on the historic Charleston earthquake of 1886 with an estimated moment magnitude $(\mathrm{Mw})$ of 7.3 with a return period of 650 years. The estimated location was near Summerville, SC. The study of historic and recorded seismicity, paleoseismic studies, and consideration of the uncertainties in the causal seismic sources current zone boundaries were used to develop the probabilistically based 1997 National Seismic Hazard maps (Frankel et al. 1996). The resulting hazard map is shown in Figure 3-1 for Peak Ground Acceleration (PGA) with a return period of 2,475 years. 


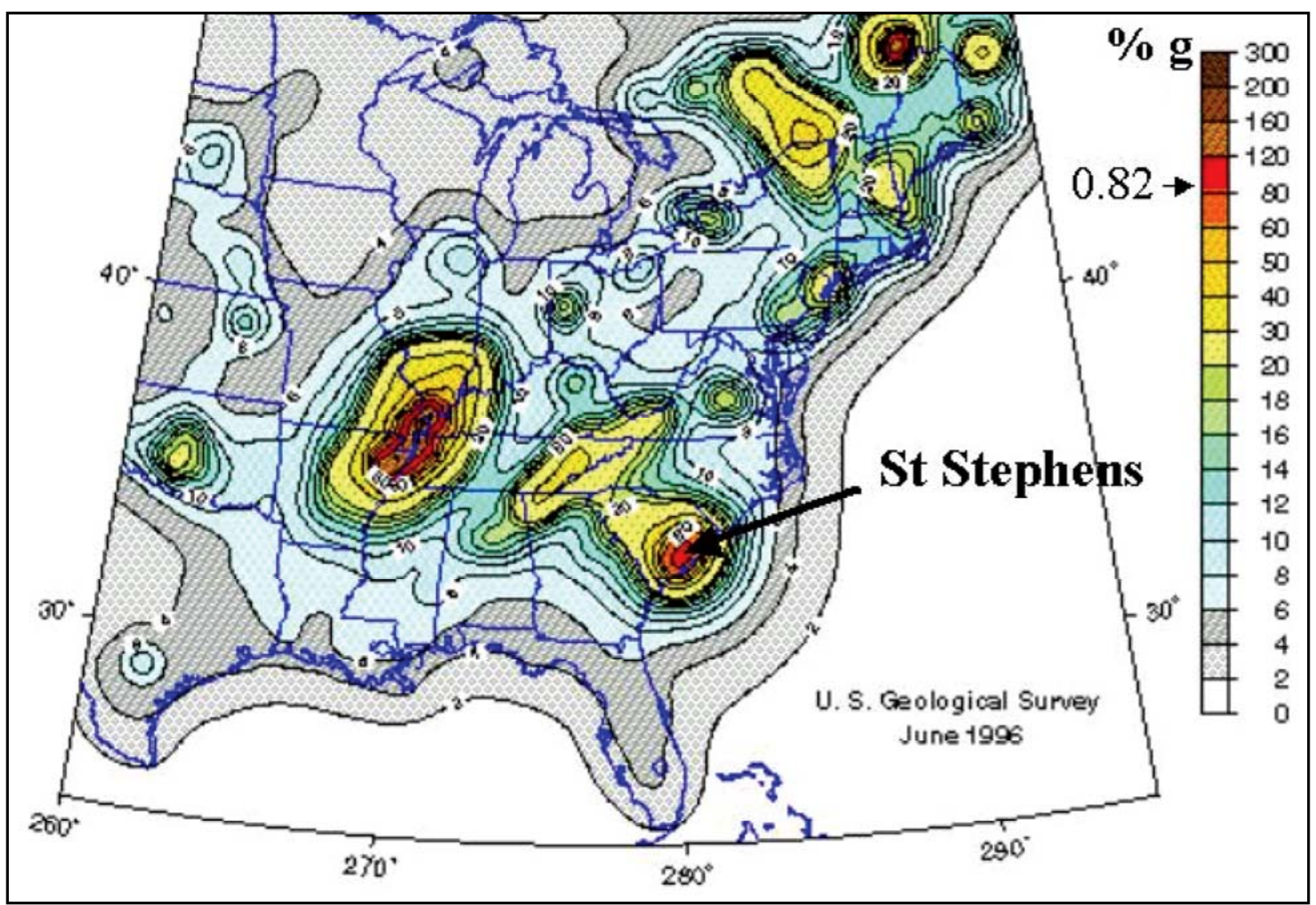

Figure 3-1. NEHRP USGS National Probabilistic Seismic Hazard Map for PGA with 2,475-year return period.

Once the International Building Code (International Code Council, Inc., 2000) provisions are adopted, earthquake design ground motions will be based on the maximum considered earthquake. These maps are a derivative of the NEHRP 1997 maps for a 2,475-year exposure, modified deterministically near active faults of the western United States. Because this site is not near a mapped active fault, the maximum considered earthquake maps provide the same motions as the 2,475-year NEHRP maps for mapped 0.2- and 1.0-sec periods. Maximum considered earthquake demands are provided in terms of acceleration response spectra for site class A and B conditions. Site class A represents a hard rock site with shear wave velocities greater than 5,000 fps. Acceleration response spectra ordinates for the maximum considered earthquake are presented in Table 3-2.

The source zone used to include the maximum historic hazard in the probabilistic maps is shown in Figure 3-2. Within this broad source zone exists a seismic "hotspot" or concentration of seismicity near Summerville, 
SC. This is the estimated location of the historic 1868 Charleston earthquake. A seismologic evaluation for this site (Krinitzsky et al. 1998) used this smaller zone in their deterministic study, proscribing an MCE of 7.5 Mw occurring within the Summerville hotspot at a closest distance of $55 \mathrm{~km}$ from the site. This deterministic approach was dictated by U.S. Army Corps of Engineers regulation due to the criticality of the embankment dam that was under evaluation.

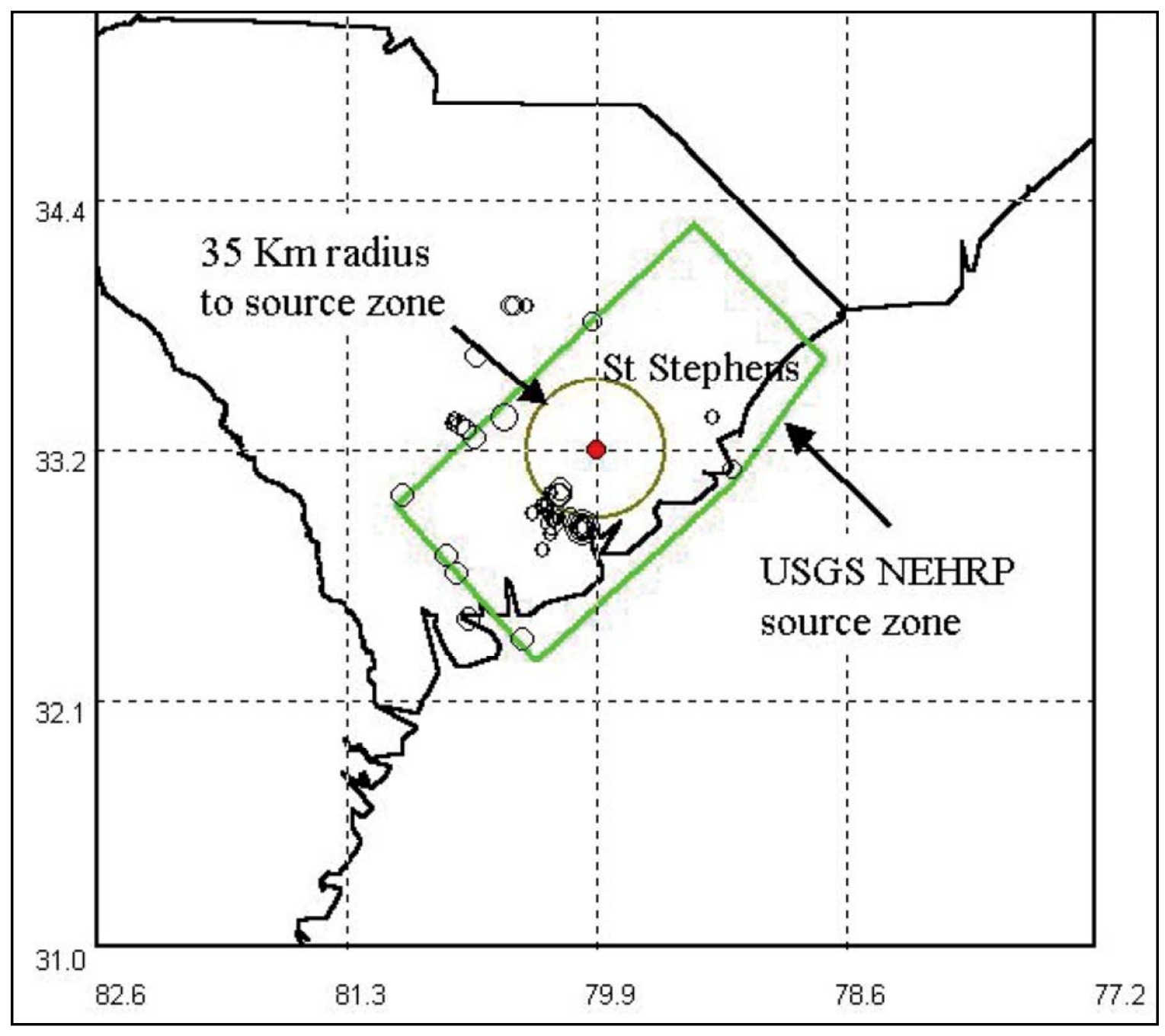

Figure 3-2. Seismicity and source zones near project site.

An updated review of current expert opinions for this area resulted in an MCE of 7.3 Mw occurring near the Summerville hotspot at a closest distance of $35 \mathrm{~km}$ from the site. This distance was based on a zone defined by the approximate boundary of the epicentral region of the 1886 event (Obermeier 1999, letter report). The source ground motion was propagated to the site with an appropriate relationship for the central-eastern 
United States (Toro et al. 1997). Ordinates for the mean and mean +1 standard deviation response spectra are provided in Table 3-3. The difference between these two recent deterministic evaluations is the use of an o.2-Mw-unit decrease in the best estimate of the 1886 event and the use of the closer distance to the source boundary of $35 \mathrm{~km}$ compared with $55 \mathrm{~km}$. These differences generally result in a moderate increase in the resulting deterministic hazard that is in better agreement with the probabilistic hazard for a 2,475-year return period that is proscribed by various recent building codes for design with performance goals of collapse prevention.

Acceleration response spectra ordinates for the MCE are presented in Table 3-3. These deterministic response spectra were developed to compare with 2,475-year equal hazard spectra developed for the collapse prevention performance evaluation. The comparison indicates that the 2,475-year motions are a safe bound and reasonable when considered with respect to the maximum historic event. A response spectrum analysis was also performed using the MCE "mean $+\sigma$ " event.

Site class B equal hazard acceleration spectra for return periods of 475, 975, and 2,475 years, the probabilistic maximum considered earthquake for site classes A and B, and the MCE mean and mean $+\sigma$ events are shown in Figure 3-3. These correspond to the information provided in Tables 3-1 through 3-3, respectively.

The characteristic ground motion period, designated as $T_{0}$ in this report, represents the intersection of the response spectrum constant acceleration range and constant velocity range. Values of $T_{0}$ equal to $0.20 \mathrm{sec}$ were selected from Figure 3-3 to represent the 2,475-year event and Toro mean $+\sigma$ event (designated as MCE $+\sigma$ in Chapter 5 ). The $T_{0}$ values are needed for determining displacement ductility demand. 


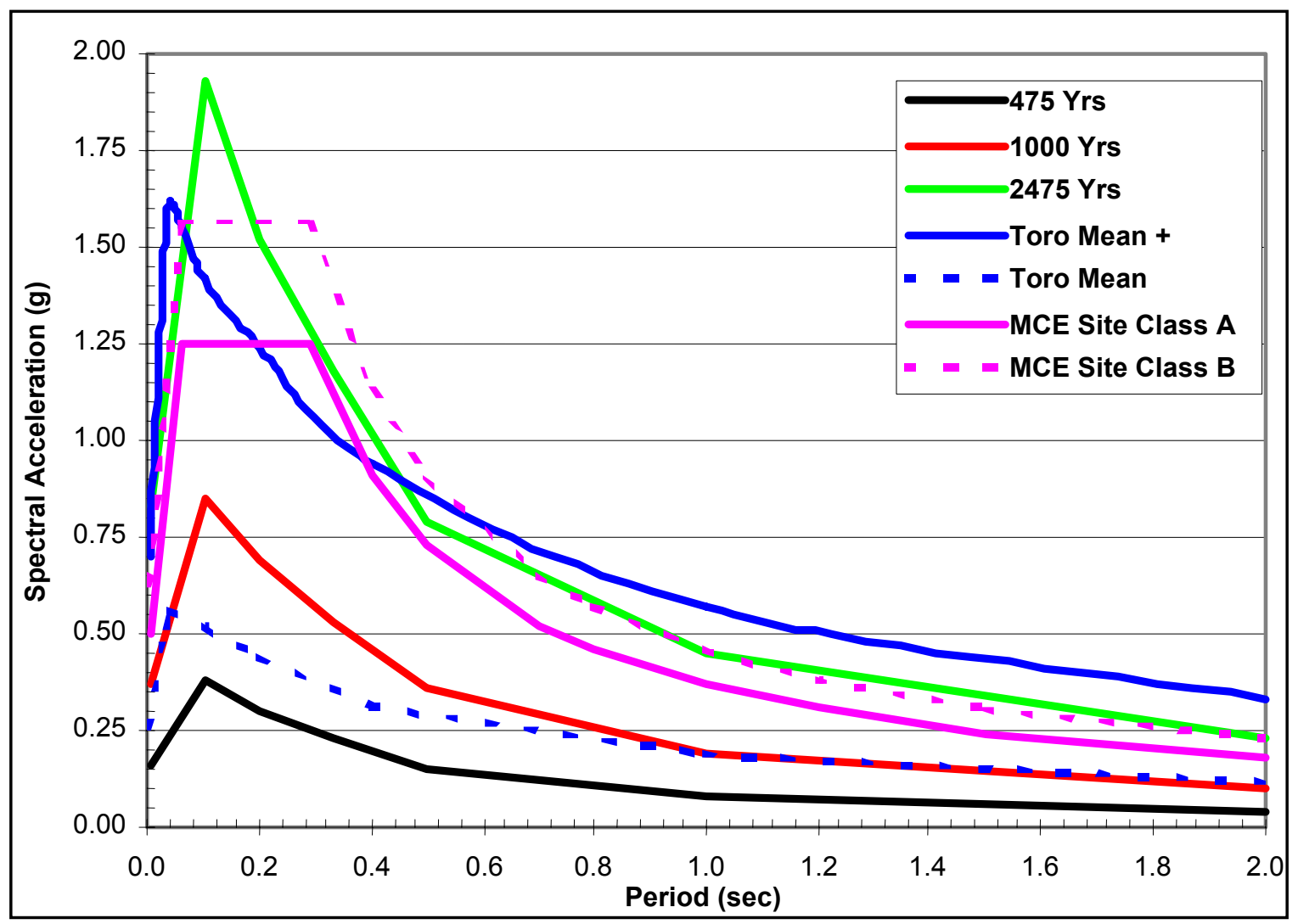

Figure 3-3. Earthquake response spectra for St. Stephen Powerhouse. Note: For Figure 3-3, $M C E=$ maximum considered earthquake. Elsewhere in the report MCE is used to represent the Maximum Credible Earthquake.

Table 3-1. Probabilistic acceleration response spectra per 1996 National Earthquake Hazards Reduction Program (NEHRP) (from Frankel et al. 1996).

\begin{tabular}{||l|l|l|l||}
\hline \multirow{2}{*}{ Period, sec } & \multicolumn{3}{|c|}{ Spectral Acceleration, g } \\
\cline { 2 - 5 } & $475-$ Year & 1,000 -Year & $2,475-$ Year \\
\hline \hline 0.00 & 0.157 & 0.366 & 0.822 \\
\hline 0.10 & 0.376 & 0.851 & 1.932 \\
\hline 0.20 & 0.300 & 0.683 & 1.514 \\
\hline 0.33 & 0.224 & 0.528 & 1.182 \\
\hline 0.50 & 0.143 & 0.355 & 0.784 \\
\hline 1.00 & 0.072 & 0.190 & 0.445 \\
\hline 2.00 & 0.035 & 0.095 & 0.227 \\
\hline
\end{tabular}


Table 3-2. Probabilistic acceleration response spectra, maximum considered earthquake for site classes $A$ and $B$, return period $=2,475$ years (from FEMA 1997b).

\begin{tabular}{|l|l|l||}
\hline $\begin{array}{l}\text { Period, } \\
\text { sec }\end{array}$ & $\begin{array}{l}\text { Spectral Acceleration Site Class A, } \\
\mathrm{g}\end{array}$ & $\begin{array}{l}\text { Spectral Acceleration Site Class B, } \\
\mathrm{g}\end{array}$ \\
\hline 0.00 & 0.500 & 0.625 \\
\hline 0.06 & 1.250 & 1.562 \\
\hline 0.29 & 1.250 & 1.562 \\
\hline 0.40 & 0.903 & 1.129 \\
\hline 0.50 & 0.723 & 0.903 \\
\hline 0.70 & 0.516 & 0.645 \\
\hline 0.80 & 0.452 & 0.565 \\
\hline 1.00 & 0.361 & 0.452 \\
\hline 1.20 & 0.301 & 0.376 \\
\hline 1.50 & 0.241 & 0.301 \\
\hline 2.00 & 0.181 & 0.226 \\
\hline
\end{tabular}

Table 3-3. Deterministic acceleration response spectra (from Toro et al. 1997).

\begin{tabular}{|l|l|l||}
\hline Period, sec & Maximum Credible Mean $+\sigma, \mathbf{g}$ & Maximum Credible Mean, $\mathbf{g}$ \\
\hline 0.00 & 0.692 & 0.251 \\
\hline 0.03 & 1.540 & 0.517 \\
\hline 0.04 & 1.615 & 0.559 \\
\hline 0.10 & 1.414 & 0.516 \\
\hline 0.20 & 1.235 & 0.434 \\
\hline 0.40 & 0.938 & 0.308 \\
\hline 1.00 & 0.562 & 0.183 \\
\hline 2.00 & 0.327 & 0.111 \\
\hline
\end{tabular}




\section{Finite Element Method Analysis}

Using the displacement-based procedure discussed in the previous chapters, an elastic response-spectrum analysis for the St. Stephen Powerhouse was performed to evaluate its seismic performance using the displacement-based procedure discussed in the previous chapters. Development of the discrete finite element method (FEM) model for elastic response analysis of the erection bay is discussed in the next section. Two-dimensional (2-D) response spectrum analysis was performed using the SAP2000 structural analysis software. The erection bay was analyzed for two site-specific motions along its weakest direction, the transverse direction. These two design spectra included 2,475-year equal hazard (probabilistic) spectrum and the $\mathrm{MCE}+\sigma$ determinisitic spectrum. Both spectra are described in Chapter 3. Response spectrum analyses were conducted to determine the effects of the two roof support boundary conditions described earlier and identified as ideal and nonideal. These two boundary conditions are expected to envelop the true inertial demands on the powerhouse superstructure walls.

\section{FEM Model}

A discrete FEM model of the generalized transverse section of the erection bay is presented in Figure 4-1. The base of the substructure is assumed fixed at el -41.o. The physical, material, and boundary conditions for the model are described in Chapter 2.

Through various parametric studies it was determined that the behavior of the composite substructure-superstructure system could be best captured using beam-column elements and lumped masses to represent the superstructure and shell elements and lumped masses to represent the substructure. The beam-column model is illustrated in Figure 4-1.

The 2-D FEM analyses presented herein are based on an analytical model that represents the entire erection bay in terms of mass and stiffness. The substructure was modeled using four-node shell elements. In general the substructure is the region below el 37.0 in the intake area, below el 17.0 in the erection bay area, and below el 57.0 in the tailrace deck area (Figure 1-3). Superstructure regions, i.e., regions above the substructure, were modeled using beam-column elements. Special beam-column 
elements, elements that could approximate the stiffening effects of the two transverse walls located in the intake area at each end of the erection bay, were used in the model. These special elements were introduced into the model at the upstream face between el 37 and el 86. The stiffening effects of the end bay wall located at the south end of the erection bay were not included in the model since the influence of the wall would be limited only to those regions of the erection bay located near the end wall. Masses were lumped at element nodal point locations. Upon completion of the FEM analysis, the total earthquake demands on various wall elements were converted to force demands per foot of wall by dividing the total demand by the erection bay width, i.e., $66 \mathrm{ft}$. This action was taken in order to compare shear and moment demands with shear and moment capacities determined on a per-foot-of-wall basis.

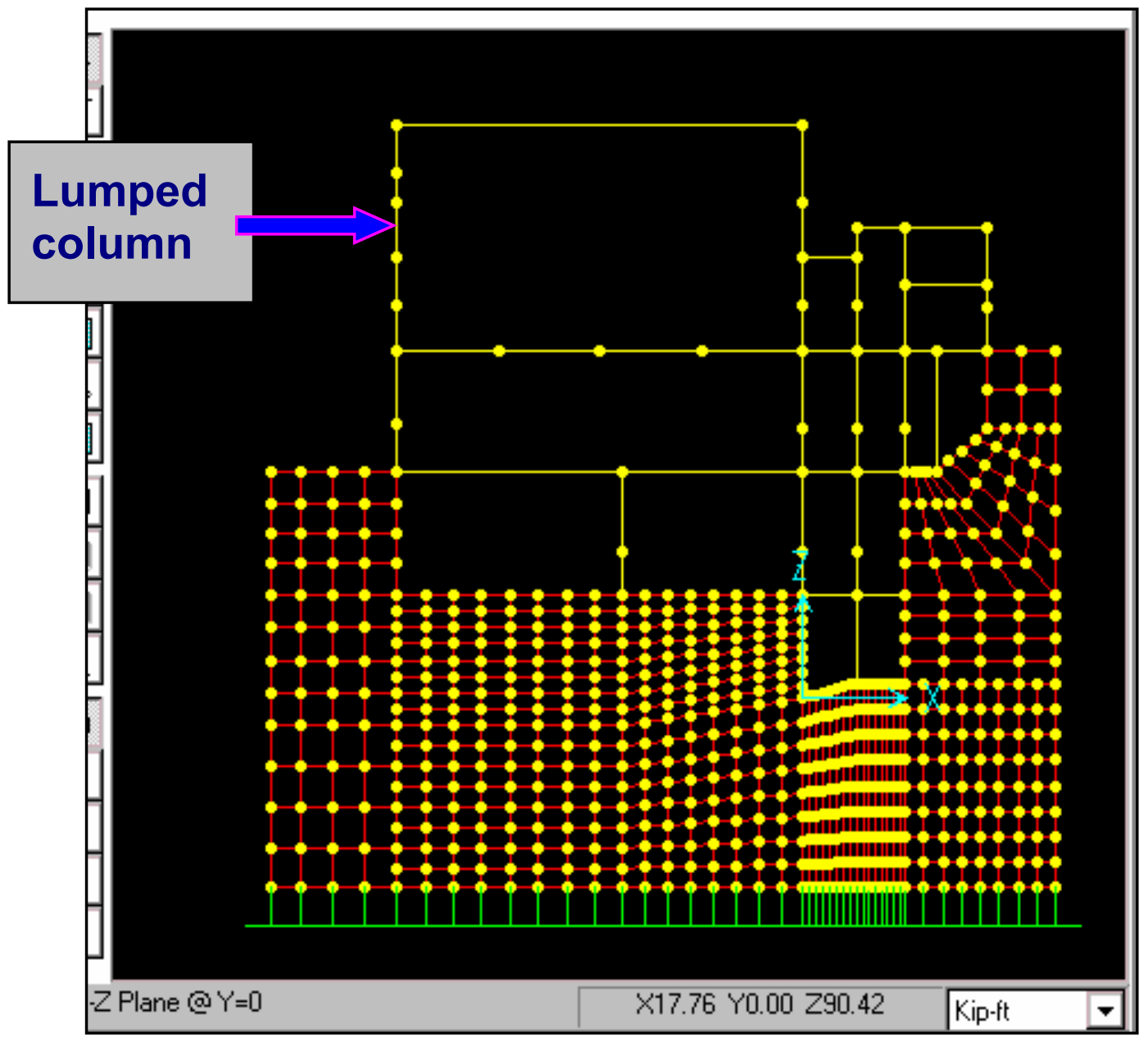

Figure 4-1. Beam-column model of the erection bay. 
An eigenvalue extraction of the lumped column model indicated that a few of the higher modes significantly contribute to the in-plane motion of the FEM model, indicating that amplification did occur in the superstructure as a result of mass participation by the substructure. Modal participation factors shown in Table 4-1 indicate the significance of modes 6 and 8 in amplifying the in-plane motions of the erection bay model.

The first three modes of vibration for the erection bay along with the higher mode 8 are displayed in Figures 4-2 through 4-5. Mode 8 illustrates the dominant influence of substructure displacement on superstructure response.

Further investigation suggested that as the period of the superstructure wall approaches the period of the substructure, in particular for ratios of wall to substructure period between one and two, the force demands on the wall increase significantly over what they would be for the wall acting alone. Higher participation factors for the substructure modes clearly indicate that the in-plane flexibility of the substructure has significant effects on the superstructure response.

Table 4-1. Modal Participation Factors (MPF).

\begin{tabular}{|l|l|l|}
\hline \multirow{2}{*}{ Mode No. } & \multicolumn{2}{|c|}{ Lumped Model } \\
\cline { 2 - 3 } & Period & MPF \\
\hline \hline 1 & 0.301 & 15 \\
\hline 2 & 0.2594 & 15 \\
\hline 3 & 0.1072 & 9 \\
\hline 4 & 0.080 & 18 \\
\hline 5 & 0.068 & 0.8 \\
\hline 6 & 0.067 & 14 \\
\hline 7 & 0.051 & 9 \\
\hline 8 & 0.030 & 33 \\
\hline 9 & 0.026 & 4 \\
\hline 10 & 0.01 & 2 \\
\hline
\end{tabular}




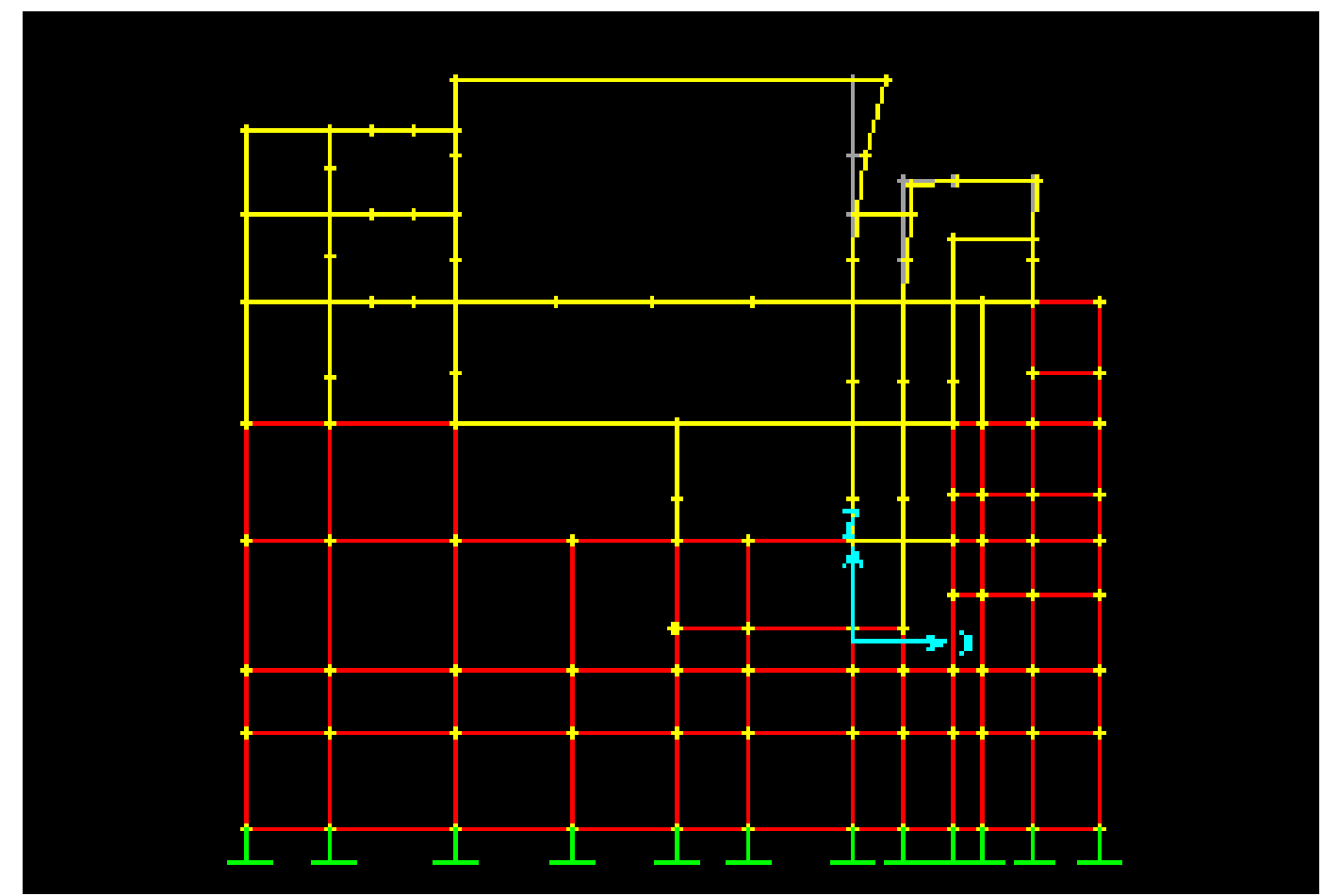

Figure 4-2. First mode of vibration for erection bay.

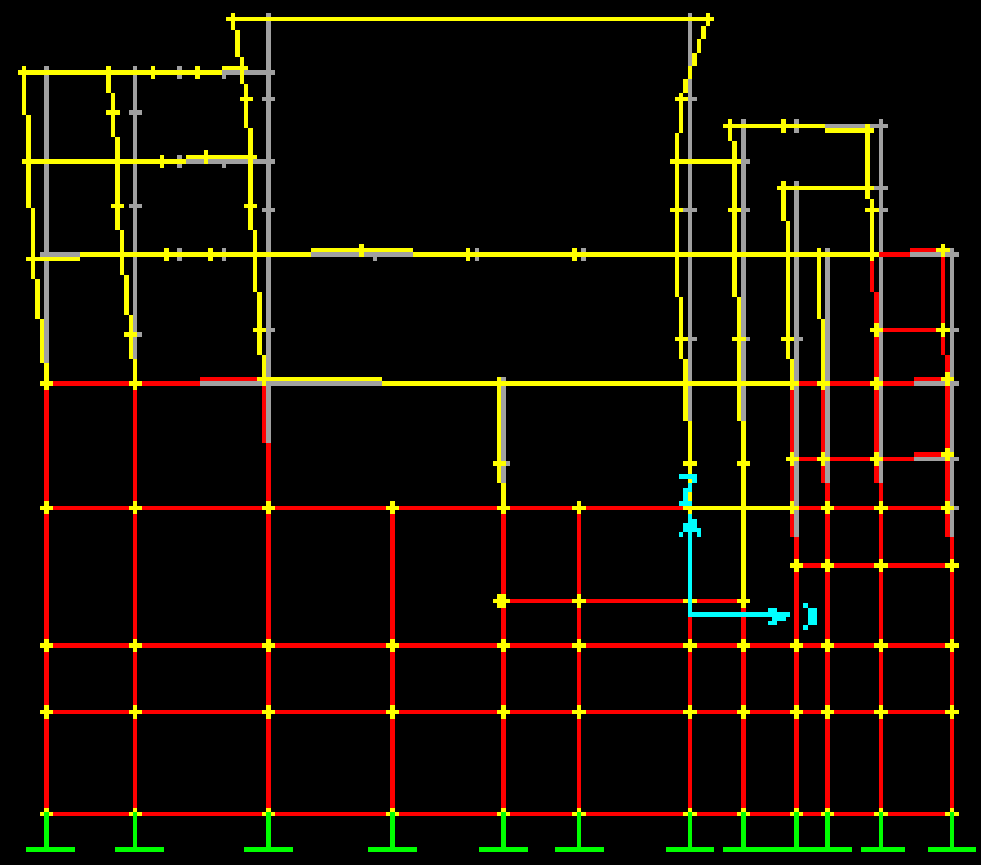

Figure 4-3. Second mode of vibration for erection bay. 


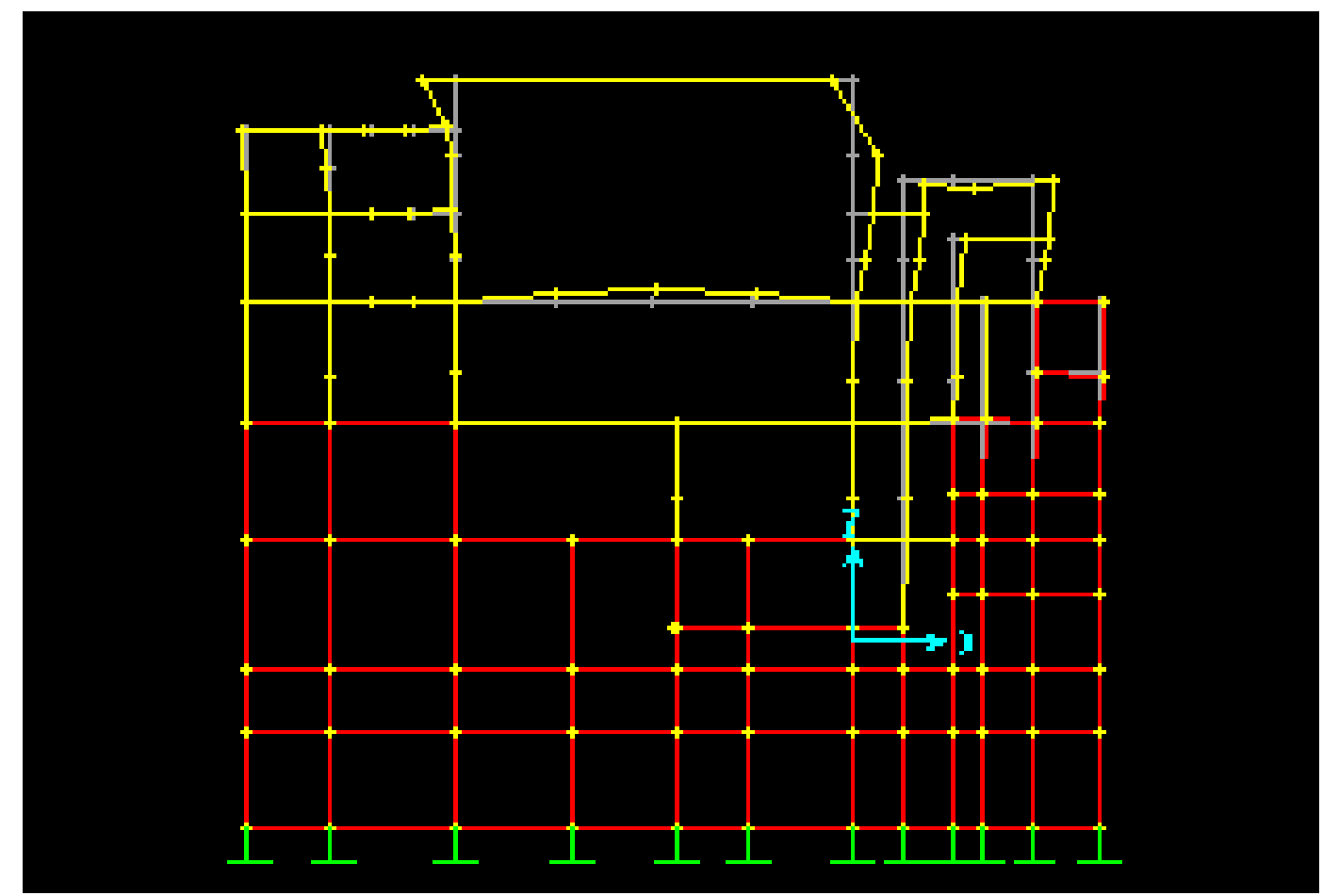

Figure 4-4. Third mode of vibration for erection bay.

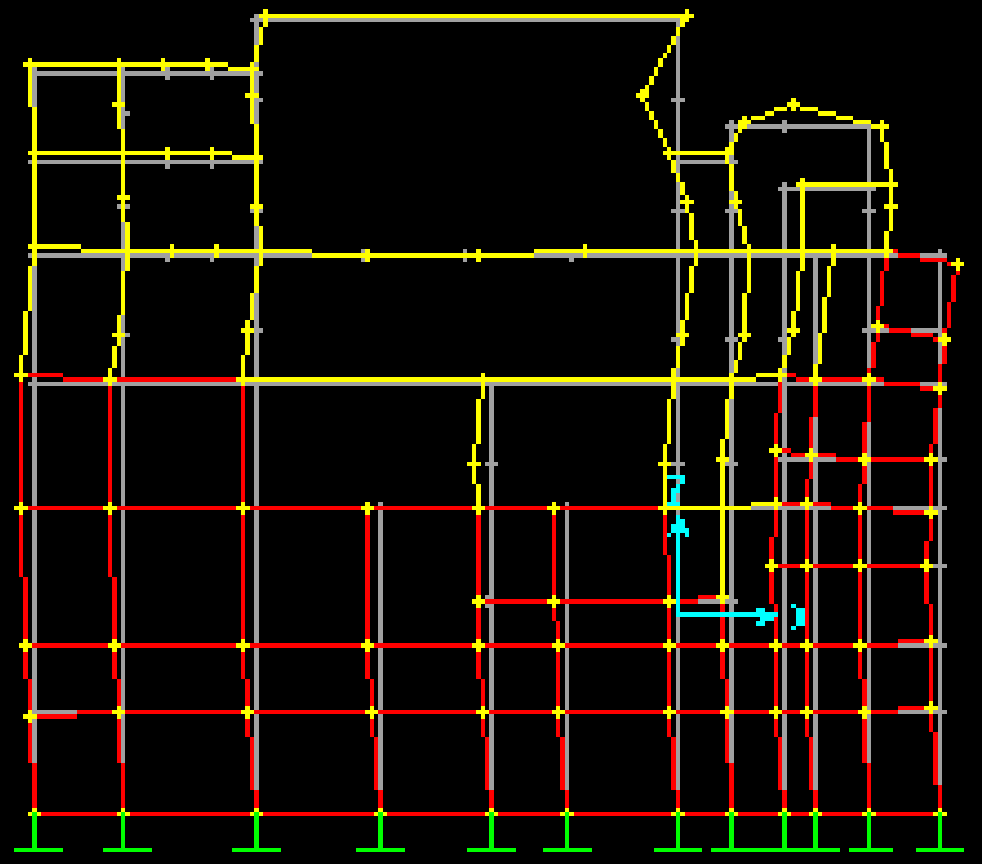

Figure 4-5. Eighth mode of vibration for erection bay. 


\section{Earthquake Demands}

The elastic response spectrum demands for ideal and nonideal support conditions for the given design response spectra are computed using the lumped mass beam-column model discussed previously. The assumptions and limitations of the current analysis are as follows:

- A lumped beam element model is used to represent substructure and superstructure.

- The substructure is fixed at the base.

- Effective widths for the wall elements are used to include the stiffness reduction from openings on walls.

- Elastic response analysis using SAP200o was based on the loaddependent Ritz method (acceleration in x-direction only). The Ritz method has proven to be a faster convergence method that yields more accurate results than the use of the same number of exact mode shapes (Wilson 1998). The Ritz method computes only the mode shapes that are excited by the seismic loading. Including over 40 modes may be required to obtain 90 percent participation using the eigenvector method.

- The out-of plane width of the model represents the entire width (66 ft) of the erection bay.

- The effective flexural stiffness, expressed as a ratio of the effective moment of inertia to the gross moment of inertia, is as indicated in Table 1-1. All substructure elements were assumed to have an effective stiffness equal to 80 percent of gross section stiffness.

- The damping is 5 percent and the design spectra are the 2,475-year probabilistic event and the deterministic MCE $+\sigma$ event.

- The T-beam is pinned at the upstream end and the roller at the downstream end for the ideal case. Both ends are pinned for the nonideal case.

- The crane mass and load are distributed equally at each support.

- Dead load and earthquake loads, i.e., demands from the response spectrum analysis, are used to compute the total demands presented in Table 4-2.

- SAP200o results for $\mathrm{U}=\mathrm{DL}+\mathrm{EQ}$, and $\mathrm{U}=\mathrm{DL}-\mathrm{EQ}$ are identical, where DL is the dead load and LL is the live load. The maximum and minimum responses for both cases, however, provide the positive or negative response spectra demands. The positive or negative response spectra demands for all cases are listed in Table 4-2. 
Figure 4-6 shows the critical locations on the erection bay model for which the earthquake demands are tabulated. Modal participation factors and their cumulative sum for both ideal and nonideal cases are shown in Table 4-3. This table indicates that inclusion of first 10 modes of the model attains over 95 percent mass participation. Table 4-3 shows the elastic response demands for critical wall locations in the erection bay. In this table, the maximum and minimum responses are presented for a load combination that includes earthquake loads, dead load, and live loads, i.e.,the crane weight applied equally as a distributed load on both upstream and downstream walls at corbel locations. Demands include the moment, shear, and axial forces for the entire 66-ft-wide section of the erection bay model.

\section{Point 1}

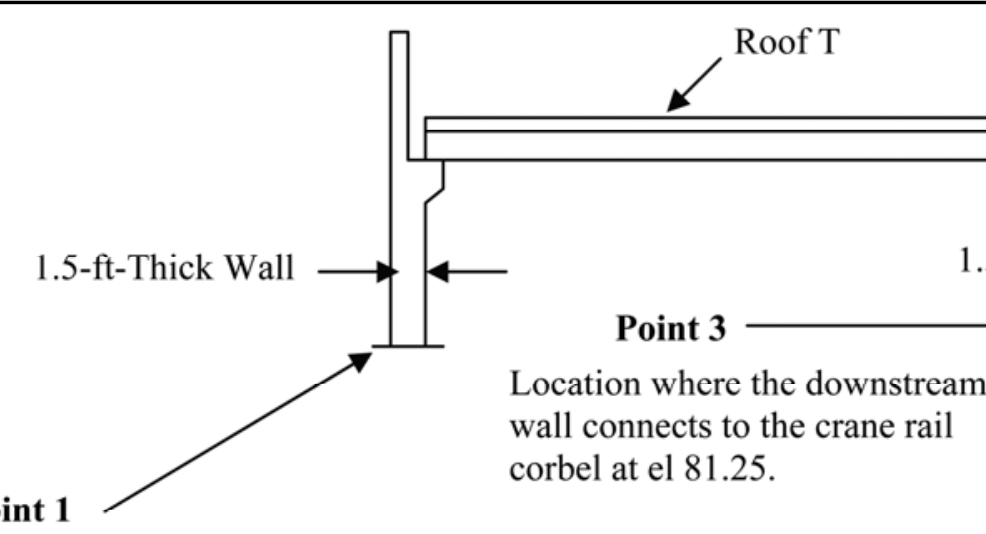

Location where the upstream wall connects to the intake deck at el 86.

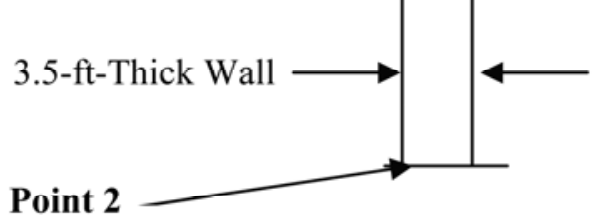

Location where the downstream wall connects to the tailrace deck at el 57.

Figure 4-6. Erection bay wall critical locations. 
Table 4-2. Member demands (SAP2000) for both NEHRP 2,474-year and MCE events for ideal and nonideal boundary conditions of the 66-ft-wide erection bay.

\begin{tabular}{|c|c|c|c|c|c|}
\hline Location & Response Spectra & Boundary Conditions & $\begin{array}{l}\text { Moment, k-ft } \\
\text { Max (Min) }\end{array}$ & $\begin{array}{l}\text { Shear, k } \\
\text { Max (Min) }\end{array}$ & $\begin{array}{l}\text { Axial, k } \\
\text { Max (Min) }\end{array}$ \\
\hline \multirow[t]{4}{*}{$\begin{array}{l}\text { Point } 1 \\
\text { El } 86.00\end{array}$} & \multirow[t]{2}{*}{ NEHRP +DL+LL } & Ideal & $\begin{array}{l}12,834 \\
(-12,579)\end{array}$ & 1,604 & $\begin{array}{l}-116 \\
(-459)\end{array}$ \\
\hline & & Nonideal & $\begin{array}{l}18,716 \\
(-18,858)\end{array}$ & $(2,397)$ & $\begin{array}{l}-114 \\
(-461)\end{array}$ \\
\hline & \multirow[t]{2}{*}{ MCE +DL+LL } & Ideal & $\begin{array}{l}7,498 \\
(-7,243)\end{array}$ & (931) & $\begin{array}{l}-156 \\
(-419)\end{array}$ \\
\hline & & Nonideal & $\begin{array}{l}9,205 \\
(-9,347)\end{array}$ & $(1,146)$ & $\begin{array}{l}-155 \\
(-420)\end{array}$ \\
\hline \multirow[t]{4}{*}{$\begin{array}{l}\text { Point } 3 \\
\text { El } 81.25\end{array}$} & \multirow[t]{2}{*}{ NEHRP +DL+LL } & Ideal & $\begin{array}{l}18,947 \\
(-19,202)\end{array}$ & $(1,505)$ & $\begin{array}{l}-242 \\
(-472)\end{array}$ \\
\hline & & Nonideal & $\begin{array}{l}7,928 \\
(-7,548)\end{array}$ & (636) & $\begin{array}{l}-239 \\
(-475)\end{array}$ \\
\hline & \multirow[t]{2}{*}{$\mathrm{MCE}+\mathrm{DL}+\mathrm{LL}$} & Ideal & $\begin{array}{l}9,705 \\
(-9,960)\end{array}$ & $(776)$ & $\begin{array}{l}-251 \\
(-462)\end{array}$ \\
\hline & & Nonideal & $\begin{array}{l}4,115 \\
(-3,736)\end{array}$ & (335) & $\begin{array}{l}-243 \\
(-471)\end{array}$ \\
\hline \multirow[t]{4}{*}{$\begin{array}{l}\text { Point } 2 \\
\text { El } 57.00\end{array}$} & \multirow[t]{2}{*}{ NEHRP +DL+LL } & Ideal & $\begin{array}{l}48,174 \\
(-48,071)\end{array}$ & $(2,100)$ & $\begin{array}{l}135 \\
(-2,475)\end{array}$ \\
\hline & & Nonideal & $\begin{array}{l}25,294 \\
(-24,044)\end{array}$ & $(1,614)$ & $\begin{array}{l}-341 \\
(-1,968)\end{array}$ \\
\hline & \multirow[t]{2}{*}{ MCE +DL+LL } & Ideal & $\begin{array}{l}24,996 \\
(-24,893)\end{array}$ & $(1,075)$ & $\begin{array}{l}-434 \\
(-1,906)\end{array}$ \\
\hline & & Nonideal & $\begin{array}{l}13,503 \\
(-12,254)\end{array}$ & (850) & $\begin{array}{l}-626 \\
(-1,684)\end{array}$ \\
\hline
\end{tabular}


Table 4-3. Modal participation factors.

\begin{tabular}{|l|l|l|l|l|l|l||}
\hline \multirow{2}{*}{ Mode No. } & \multicolumn{3}{|c|}{ Ideal } & \multicolumn{3}{c|}{ Nonldeal } \\
\cline { 2 - 7 } & Period & UX & $\Sigma$ UX & Period & UX & $\Sigma$ UX \\
\hline \hline 1 & 0.301 & 8.2 & 8.2 & 0.283 & 16.4 & 16.4 \\
\hline 2 & 0.259 & 8.6 & 16.8 & 0.115 & 0.0 & 16.4 \\
\hline 3 & 0.107 & 3.3 & 20.3 & 0.102 & 7.1 & 23.5 \\
\hline 4 & 0.081 & 12.3 & 32.7 & 0.075 & 12.9 & 36.1 \\
\hline 5 & 0.070 & 5.4 & 38.1 & 0.069 & 1.6 & 38.1 \\
\hline 6 & 0.058 & 2.5 & 40.6 & 0.057 & 2.8 & 40.9 \\
\hline 7 & 0.049 & 5.3 & 45.9 & 0.047 & 5.9 & 46.9 \\
\hline 8 & 0.038 & 6.4 & 52.3 & 0.035 & 8.3 & 55.1 \\
\hline 9 & 0.027 & 32.9 & 85.2 & 0.026 & 30.9 & 86.0 \\
\hline 10 & 0.013 & 10.4 & 95.6 & 0.012 & 10.1 & 96.1 \\
\hline
\end{tabular}




\section{Summary of Analysis Results for St. Stephen Erection Bay Walls}

In the preceding chapters the process for obtaining elastic force demands, inelastic displacement demands, and displacement ductility demands based on the results of response spectrum analyses was described. Methods used to determine force, displacement, and displacement ductility capacities were also described. From this information DCRs were determined. With respect to shear and sliding shear failure mechanisms, demands should not exceed capacities, or the DCR should be less than or equal to $1(\mathrm{DCR} \leq 1.0)$. A demand-to-capacity limit of 1 is placed on shear and sliding shear because these are brittle failure mechanisms. A potential for collapse of the superstructure exists whenever the DCR for shear and sliding shear exceeds 1.

The DCR for flexure can exceed 1 provided the displacement ductility demand does not exceed the displacement ductility capacity. On a flexural displacement ductility basis the DCR should be less than or equal to 1 (DCR $\leq 1.0)$. Whenever the flexural displacement ductility demand to capacity exceeds 1 , rebar splices can fail or reinforcing steel can fracture. Both effects can lead to collapse of the superstructure. The locations in the erection bay superstructure where inelastic action will take place during major earthquakes as described previously are designated as Points 1, 2, and 3 and illustrated on Figure 5-1.

The maximum demands on these plastic hinge regions from the $\mathrm{MDE}+\sigma$, 2,475-, 1,000-, and 475-year earthquakes are presented in Tables 5-1 through 5-4, respectively. Demands are expressed in terms of moments, shears, and displacement ductility. Response spectrum analyses for the 1,000- and 475-year equal hazard spectra were not performed. The response spectrum analyses, however, are linear elastic and the equal hazard spectra scale uniformly with respect to all periods of vibration. Therefore the demands for the 1,000- and 475-year events for a given period of vibration can be estimated based on the ratio of the spectral acceleration for the event under consideration (1,000- or 475-year) to the spectral acceleration for the 2,475-year event. This ratio is equal to 0.45 for the 1,000-year event and 0.20 for the 475-year event. The demands for each location (Points 1, 2, or 3) represent the maximum demands from the 
ideal or nonideal boundary condition analytical model. The nonideal condition produces the greatest demands at Point 1 . The ideal condition produces the greatest demands at Points 2 and 3 .

The capacities of the various members for the plastic hinge regions illustrated in Figure 5-1 are also provided in Tables 5-1 through 5-4. As with demand, capacities are expressed in terms of moments, shears, and displacement ductility.

The DCRs for each plastic hinge region, for the MDE $+\sigma, 2,475^{-}, 1,000-$ and 475-year earthquakes are also presented in Tables 5-1 through 5-4, respectively. When the DCR exceeds the allowable value, it is listed in bold text. As one can see from the tables, failure mechanisms that can lead to collapse of the erection bay superstructure can develop for all but the 475-year event, although the number of potential failure mechanisms decrease as earthquake demands are reduced.

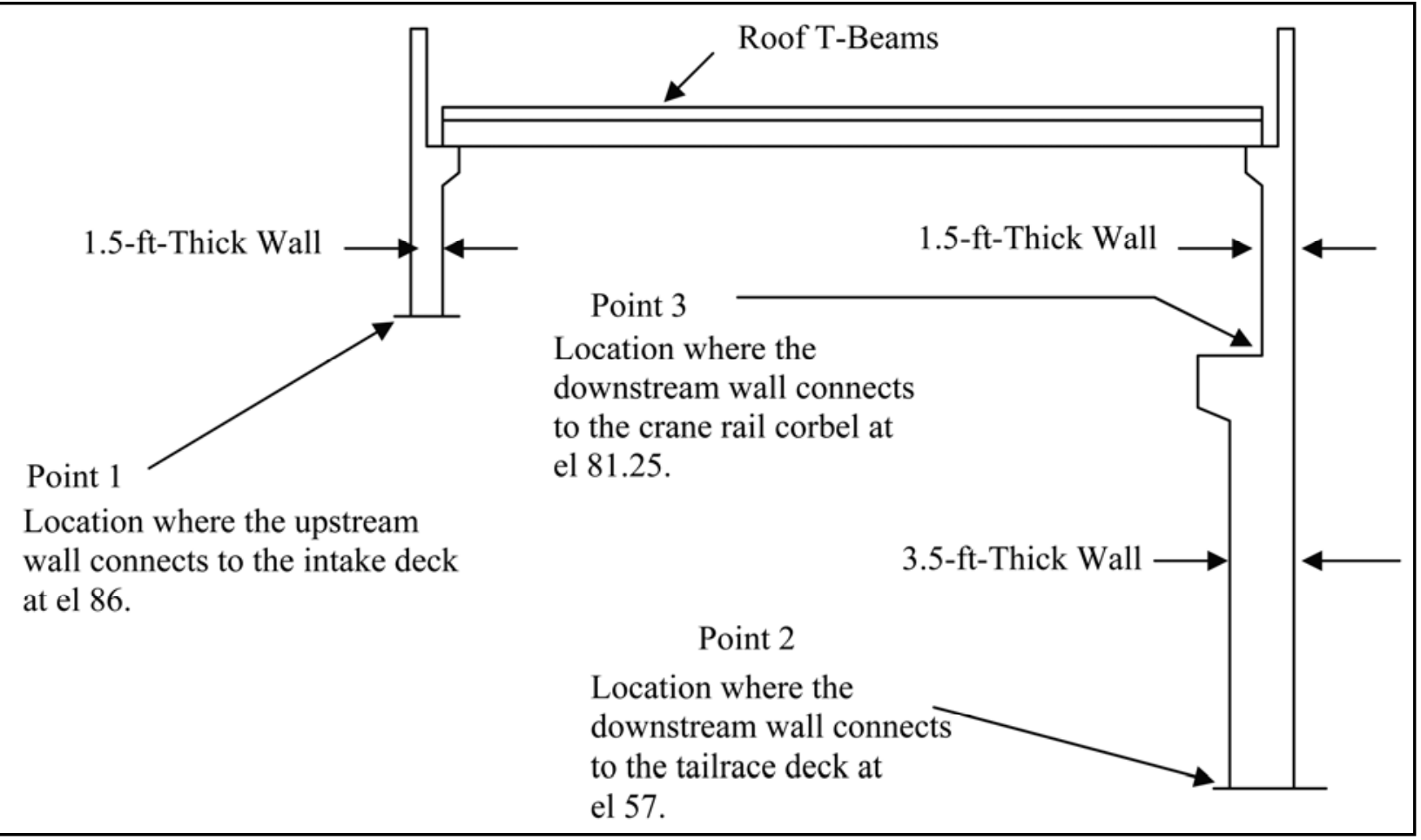

Figure 5-1. Erection bay superstructure plastic hinge locations (yield regions).

Force demands and capacities as presented in the tables are based on a unit length of wall ( $1 \mathrm{ft}$ ). Moments are in kip-feet and shears are in kips. 
Although the displacement demands were not provided in the tables, the inelastic displacements at the roof level for the MCE $+\sigma$ and 2,475-year equal hazard event were approximately $1 \mathrm{ft}$. A displacement of this magnitude will place severe demands on the T-beam to roof connections and most likely lead to a loss of support for the T-beams.

The maximum lateral force demand on roof fixed bearings is approximately equal to the maximum shear at Point 1 . From the shear demand information in the tables it can be seen that except for the 475-year event, the lateral force demand will exceed the fixed bearing weld capacity, i.e., 11 kips per foot (see calculations in Chapter 1).

Table 5-1. MCE $+\sigma$ earthquake.

\begin{tabular}{|l|l|l|l|l|l|l|l|l|l||}
\hline \multirow{2}{*}{ Quantity } & \multicolumn{3}{|c|}{ Point 1, Nonideal } & \multicolumn{3}{c|}{ Point 2, Ideal } & \multicolumn{3}{c|}{ Point 3, Ideal } \\
\cline { 2 - 11 } & Demand & Capacity & DCR & Demand & Capacity & DCR & Demand & Capacity & DCR \\
\hline Displ. Duct. & 9.9 & 7.0 & 1.4 & 2.3 & 3.0 & 0.77 & 4.6 & 4.5 & 1.1 \\
\hline Moment & 139 & 33 & 4.2 & 379 & 162 & 2.4 & 151 & 33 & 4.6 \\
\hline Shear & 17.4 & 11.6 & 1.5 & 16.3 & 27.0 & 0.60 & 11.8 & 11.6 & 1.0 \\
\hline $\begin{array}{l}\text { Sliding } \\
\text { Shear }\end{array}$ & 17.4 & 17.5 & 1.0 & 16.3 & 41.0 & 0.40 & 11.8 & 17.5 & 0.67 \\
\hline \hline
\end{tabular}

Note: Moment, shear, and sliding shear demands are per foot of wall and are equal to the demands for the entire erection bay (Table 4-3 values) divided by the erection bay width of 66-ft. Moments in the table are in $\mathrm{ft}-\mathrm{kips} /$ foot of wall. Shear and sliding shear are in kips/foot of wall.

Table 5-2. NEHRP 2,475-year earthquake demands.

\begin{tabular}{|l|l|l|l|l|l|l|l|l|l||}
\hline \multirow{2}{*}{ Quantity } & \multicolumn{3}{|c|}{ Point 1, Nonideal } & \multicolumn{3}{c|}{ Point 2, Ideal } & \multicolumn{3}{c|}{ Point 3, Ideal } \\
\cline { 2 - 11 } & Demand & Capacity & DCR & Demand & Capacity & DCR & Demand & Capacity & DCR \\
\hline \hline Displ. Duct. & 24.0 & 7.0 & 3.4 & 4.5 & 3.0 & 1.5 & 8.8 & 4.5 & 2.0 \\
\hline Moment & 286 & 33 & 8.7 & 730 & 162 & 4.5 & 291 & 33 & 8.8 \\
\hline Shear & 36.0 & 11.6 & 3.1 & 31.8 & 27.0 & 1.2 & 22.8 & 11.6 & 2.0 \\
\hline $\begin{array}{l}\text { Sliding } \\
\text { Shear }\end{array}$ & 36.0 & 17.5 & 2.1 & 31.8 & 41.0 & 0.78 & 22.8 & 17.5 & 1.3 \\
\hline \hline
\end{tabular}

Note: Moment, shear, and sliding shear demands are per foot of wall and are equal to the demands for the entire erection bay (Table 4-3 values) divided by the erection bay width of 66 -ft. Moments in the table are in ft-kips/foot of wall. Shear and sliding shear are in kips/foot of wall. 
Table 5-3. NEHRP 1,000-year earthquake demands.

\begin{tabular}{|l|l|l|l|l|l|l|l|l|l|}
\hline \multirow{2}{*}{ Quantity } & \multicolumn{3}{|c|}{ Point 1, Nonideal } & \multicolumn{3}{c|}{ Point 2, Ideal } & \multicolumn{3}{c|}{ Point 3, Ideal } \\
\cline { 2 - 11 } & Demand & Capacity & DCR & Demand & Capacity & DCR & Demand & Capacity & DCR \\
\hline \hline Displ. Duct. & 9.7 & 7.0 & 1.4 & 2.0 & 3.0 & 0.67 & 4.0 & 4.5 & 0.89 \\
\hline Moment & 129 & 33 & 3.9 & 329 & 162 & 2.0 & 131 & 33 & 4.0 \\
\hline Shear & 16.2 & 11.6 & 1.4 & 14.3 & 27.0 & 0.53 & 10.3 & 11.6 & 0.89 \\
\hline $\begin{array}{l}\text { Sliding } \\
\text { Shear }\end{array}$ & 16.2 & 17.5 & 0.93 & 14.3 & 41.0 & 0.35 & 10.3 & 17.5 & 0.59 \\
\hline \hline
\end{tabular}

Note: Moment, shear, and sliding shear demands are per foot of wall and equal to the values from Table 5-2 times 0.45 . Moments in the table are in ft-kips/foot of wall. Shear and sliding shear are in kips/foot of wall.

Table 5-4. NEHRP 475-year earthquake demands.

\begin{tabular}{|l|l|l|l|l|l|l|l|l|l||}
\hline \multirow{2}{*}{ Quantity } & \multicolumn{4}{|c|}{ Point 1, Nonideal } & \multicolumn{3}{c||}{ Point 2, Ideal } & \multicolumn{3}{c||}{ Point 3, Ideal } \\
\cline { 2 - 12 } & Demand & Capacity & DCR & Demand & Capacity & DCR & Demand & Capacity & DCR \\
\hline \hline Displ. Duct. & 3.2 & 7.0 & 0.45 & 0.9 & 3.0 & 0.30 & 1.8 & 4.5 & 0.40 \\
\hline Moment & 57 & 33 & 1.7 & 146 & 162 & 0.90 & 58 & 33 & 1.8 \\
\hline Shear & 7.2 & 11.6 & 0.62 & 6.4 & 27.0 & 0.24 & 4.6 & 11.6 & 0.40 \\
\hline $\begin{array}{l}\text { Sliding } \\
\text { Shear }\end{array}$ & 7.2 & 17.5 & 0.41 & 6.4 & 41.0 & 0.16 & 4.6 & 17.5 & 0.26 \\
\hline $\begin{array}{l}\text { Note: Moment, shear, and sliding shear demands are per foot of wall and equal to the values from Table 5-2 } \\
\text { times 0.20. Moments in the above table are in ft-kips / foot of wall. Shear and sliding shear are in kips / foot } \\
\text { Of wall. }\end{array}$ \\
\hline
\end{tabular}

It must be recognized that the shear demands indicated in these tables were obtained from the elastic response spectrum analysis and therefore represent the shear demands the structure would experience if it remained elastic. It is clear from the DCRs for moment and shear in these tables that there is a hierarchy in the formation of failure mechanisms and that flexural yielding will occur before shear demands reach their tabular values. In reality, maximum shear demands will be limited to values associated with the onset of flexural yielding. The shear demands, however, should consider the potential increase in moment capacity due to strain hardening in the steel, i.e., an increase in steel tensile capacity as a result of strain hardening will lead to an increase in moment capacity. Normally the moment capacity increase due to strain hardening is in the order of 50 percent. 
Failure will likely not be due to shear or roof bearing connection failure, but will be due to mechanisms associated with inelastic actions in plastic hinge regions. This means failure will be due either to fracturing of the flexural reinforcing steel or to failure of flexural steel rebar splices located in plastic hinge regions (Table 2-1).

Sample calculations illustrating the process used to determine displacement ductility demand and displacement ductility capacity are illustrated in Table 5-5. 
Table 5-5. Sample calculation for upstream wall displacement ductility capacity, Point 1 (el 86).

Displacement Ductility Demand to Capacity Evaluation St Stephen PH Erection Bay

Evaluate the 1.5 foot thick section of the upstream wall

April 25, $2000 \quad$ File: Ductility 1.5 U/S Foot Wall

\section{Displacement Ductility Capacity}

$$
\begin{aligned}
& \phi_{\mathrm{y}}:=0.000119 \text { rads / inch } \\
& \phi_{\mathrm{u}}:=0.002428 \quad \text { rads } / \text { inch } \\
& \mathrm{F}_{\mathrm{y}}:=40.0 \mathrm{KSI} \\
& \mathrm{d}_{\mathrm{b}}:=0.875 \quad \text { inches } \\
& \mathrm{L}_{\mathrm{p}}:=0.3 \cdot \mathrm{F}_{\mathrm{y}} \cdot \mathrm{d}_{\mathrm{b}} \\
& \mathrm{L}_{\mathrm{p}}=10.5 \quad \text { inches Analysis } \\
& \mathrm{L}_{\mathrm{eff}}:=96.0 \quad \text { inches } \\
& \left.\mu:=1+3 \cdot\left(\frac{\phi_{\mathrm{u}}}{\phi_{\mathrm{y}}}\right)-1\right] \cdot\left(\frac{\mathrm{L}_{\mathrm{p}}}{\mathrm{L}_{\mathrm{eff}}}\right) \cdot\left[1-0.5 \cdot \frac{\mathrm{L}_{\mathrm{p}}}{\mathrm{L}_{\mathrm{eff}}}\right] \\
& \mu=7.019 \quad \text { Ductility capacity }
\end{aligned}
$$


Table 5-5 (continued)

Sample calculation for upstream wall displacement ductility demand Point 1 (el 86)

2,475-year event nonideal roof bearing support condition

NEHRP TR $=2475$ Years

Displacement Ductility Demand

$$
\begin{aligned}
& \mathrm{M}_{\mathrm{DE}}:=286 \quad \text { Ft-Kips } \\
& \mathrm{M}_{\mathrm{N}}:=33 \quad \text { Ft-Kips } \\
& \mathrm{T}_{0}:=0.20 \quad \text { Seconds } \\
& \mathrm{T}_{\mathrm{S}}:=0.10 \quad \text { Seconds } \\
& \mathrm{R}_{\mathrm{REQD}}:=\frac{\mathrm{M}_{\mathrm{DE}}}{\mathrm{M}_{\mathrm{N}}} \\
& \mathrm{R}_{\mathrm{REQD}}=8.667
\end{aligned}
$$

Priestley Equation for Ductility Demand

$\mu_{\mathrm{DP}}:=1.5 \cdot\left(\mathrm{R}_{\mathrm{REQD}^{-}}-1\right) \cdot\left(\frac{\mathrm{T}_{0}}{\mathrm{~T}_{\mathrm{S}}}\right)+1$

$\mu_{\mathrm{DP}}=24 \quad$ Use for ductility demand 


\section{Conclusions}

A performance-based analysis was used to assess the seismic performance of St. Stephen powerhouse erection bay. Two site-specific design response spectra were used to evaluate the structure, a 2,475-year probabilistic earthquake event and a deterministic $\mathrm{MCE}+\sigma$ event.

The St. Stephen Powerhouse superstructure is vulnerable to collapse for earthquake hazards with return periods greater than 500 years. The structure does not meet the basic safety objective (collapse prevention) of FEMA 356.

A memorandum summarizing a meeting held to review the seismic stability of St. Stephen Hydropower Plant is presented in Appendix A.

A memorandum describing the Corps of Engineers Hazard Reduction Program Powerhouse Evaluation Criteria is presented in Appendix B. 


\section{References}

American Concrete Institute. Building code requirements for reinforced concrete. ACI 318. Detroit, MI.

American Institute of Steel Construction, Inc. 1994. Load and resistance factor design: Manual of steel construction. 2nd ed. Chicago, IL.

Chandler, A. M., and P. A. Mendis. 2000. Performance of reinforced concrete frames using force and displacement based seismic assessment methods. Engineering Structures 22: $352-363$.

Computers and Structures, Inc. 1997. SAP200o: Integrated finite element analysis and design of structures. Berkeley, CA.

Ehsani, M. R., and M. E. Marine. 1994. Computer program for concrete momentcurvature relationship (M-Phi). Contract Letter Report. Vicksburg, MS: U.S. Army Engineer Waterways Experiment Station.

Federal Emergency Management Agency. 1997a. NEHRP guidelines for the seismic rehabilitation of buildings. FEMA Publication 273. Prepared for the Building Seismic Safety Council, Washington, DC, by the Applied Technology Council (ATC-33 Project), Redwood City, CA, with funding by the Federal Emergency Management Agency, Washington, DC.

Federal Emergency Management Agency. 1997b. NEHRP recommended provisions (National Earthquake Hazards Reduction Program) for seismic regulations for new buildings and other structures. FEMA Publication 302. Prepared by the Building Seismic Safety Council, Washington, DC, for the Federal Emergency Management Agency, Washington, DC.

Federal Emergency Management Agency. 2000. Prestandard and commentary for the seismic rehabilitation of buildings. FEMA 356. Prepared by American Society of Civil Engineers, Reston, VA, for Federal Emergency Management Agency, Washington, DC.

Frankel, A., C. Mueller, T. Barnhard, D. Perkins, E. V. Leyendecker, N. Dickman, S. Hanson, and M. Hopper. 1996. National Seismic-Hazard Maps: Documentation June 1996. Open-File Report 96-532. Denver, CO: U.S. Department of the Interior, U.S. Geological Survey. http://earthquake.usgs.gov/research/hazmaps/publications/docmaps.php

International Code Council, Inc. 2000. International building code. Falls Church, VA.

Krinitzsky, E. L., M. E. Hynes, D. E. Yule, R. S. Olsen. 1998. A geologic-seismologic evaluation of earthquake hazards at St. Stephen Powerhouse, Cooper River Rediversion Project, South Carolina, and Newmark-sliding-block deformation analysis of embankments. TR-GL-98-4. Vicksburg, MS: U.S. Army Engineer Waterways Experiment Station. 
Medhekar. M. S., and D. J. L. Kennedy. 2000. Displacement based seismic design of buildings-theory. Engineering Structures 22: 201-209.

Moehle, J. P. 1992. Displacement-based design of RC structures subjected to earthquake. Earthquake Spectra 8 (3): 404-428.

Paulay, T., and M. J. N. Priestley. 1992. Seismic design of reinforced concrete and masonry buildings. Hoboken, NJ: John Wiley.

Precast/Prestressed Concrete Institute. 1999. PCI design handbook. 5th ed. Chicago, IL.

Strom, R. W., and R. M. Ebeling. 2005. Appendix G: Criteria review for Corps by Dr. Priestley and Dr. Moehle. In Seismic structural considerations for the stem and base of retaining walls subjected to earthquake ground motions, G-6-G-12. ERDC/ITL TR-05-3. Vicksburg, MS: U.S. Army Engineer Research and Development Center.

Toro, G. R., N. A. Abrahamson, J. F. Schneider. 1997. Model of strong ground motions from earthquakes in central and eastern North America: Best estimates and uncertainties. Seismological Research Letters 68 (1).

Wilson, E. L. 1998. The three dimensional dynamic analysis of structures with emphasis on earthquake engineering. 2nd ed. Berkeley, CA: Computers and Structures, Inc. 


\section{Appendix A}

CECW-EG

5 May 2000

MEMO FOR CECW-E

CECW-O

SUBJECT: Seismic Stability of St. Steven's Hydropower Plant, South Carolina

1. Summary. At the request of CESAD and CESAC, a meeting was held to review the seismic stability of St. Steven's Hydropower Plant, South Carolina. In conjunction with a presentation on the development of design ground motions and structural analysis of the project, it was determined that, based on existing guidance in ER 1110-2-1806, the St. Steven's Hydropower Plant is not a "critical" structure.

2. Place and Date. Information Technology Laboratory, Waterways Experiment Station, Vicksburg, Mississippi, 2 May 2000.

3. Attendees: Jerry Foster, CECW-ET, Michael Klosterman, CECW-EG; Byron Foster, CESAD-ET-E, Wayne Bieganowsky, CESAC-TS-DF, Robert Ebeling, CEERD-ID-P, Wayne Jones, CEERD-ID-P, Robert Hall, CEERDSS-A, Mostafiz Chowdhury, CEERD-SS-A, Don Yule, CEERD-GG-H, Dr. Collins, FERC (conference phone), Ralph Strom, consultant, and Wayne Jones, CEERD-ID-P, visitor.

4. Purpose. To review the seismic stability of St. Steven's Hydropower Plant, South Carolina.

5. Background. St. Steven's Hydropower Plant is located on the Santee River and is part of the Pinopolous Reservoir system near Charleston, South Carolina. The project was completed in 1985 and is being reevaluated for seismic stability on a 15-year cycle in accordance with ER 1110-2-1806, Earthquake Design and Evaluation for Civil works Projects. Significant advances in the state-of-the-art of earthquake engineering have occurred since the project was completed and led the district to believe that the dam would be a candidate for remediation under the Dam Safety 
Assurance Program. Design ground motions and structural analysis of the project were performed based on these recent advances. Interpretation of ER 1110-2-1806 led the district and CEERD personnel to conclude that the St. Steven's Hydropower Plant was a critical structure and subject to the new NEHRP guidelines (FEMA-273 \& FEMA-274).

\section{Discussion.}

a. Criticality of the structure.

(1) According to guidance contained in ER 1110-2-1806, para. 5.a. and Appendix B, "Critical features are the engineering structures ...whose failure during or immediately following an earthquake could result in loss of life. Loss of life potential (is) based upon inundation mapping of (the) area downstream of the project." The most likely failure scenarios developed for the St. Steven's hydropower plant indicate there is no incremental loss of life downstream of the structure due to its failure during an earthquake event.

(2) Other dams in the Santee-Pinopolous Reservoir system control the consequences of failure that would occur during a major seismic event. The failure of St. Steven's powerhouse would have no incremental impact on loss of life downstream.

(3) ER 1110-2-1806, para. 8.b. indicates that "Minimum standards for the seismic design or evaluation of (occupied) buildings ...are available in national, regional, or local building codes." The presence of USACE personnel in a structure does not qualify the structure for the 'critical' designation of para. 5.a. of ER 1110-21806. The National Earthquake Hazard Reduction Program (NEHRP) is designed to insure the safety of personnel in USACE and other Federal buildings in accordance with PL 101-610 and Executive Order 12941. The seismic safety of all USACE buildings has been evaluated under this program. The district should verify the seismic risk assigned to the St. Steven's hydropower plant during these evaluations. The program proponent is Helen Petersen, CENWD (503-808-3833). 
b. Appropriate ground motions. Probabilistic ground motions are obtained from ER 1110-2-1806, Appendix D. Appendix D consists of 1991 USGS seismic maps; a 1998 revision has updated this appendix to the 1995 USGS/NEHRP seismic maps. The most recent 1997 NEHRP seismic maps have not been adopted for use in ER 1110-2- 1806. At the present time ground motions used to evaluate civil works projects will be obtained using the 1995 USGS/NEHRP seismic maps.

c. Future revisions to ER 111 0-2-1806 may incorporate concepts addressed in FEMA 273 and 274. At the present time, all policy and guidance regarding earthquake design and evaluation for civil works projects is contained in the existing ER 1110-2- 1806.

7. Future Action. The St. Steven's Hydropower Plant should be evaluated as a noncritical structure according to the requirements of (ER 1110-21806. It should be demonstrated that the structure can withstand the MDE for noncritical structures (ER 1110-2-1806, para. 5d and para. 6b. Any justification for proposed remediation to withstand seismic loads in excess of the MDE must be based upon an economic analysis in-accordance with guidance for the Major Rehabilitation Program.

JERRY FOSTER, PE MICHAEL J. KLOSTERMAN, RPG

Structural Engineer, CECW-ET Chief Geologist, CECW-EG 


\section{Appendix B}

CENWD-MT-ES

29 October 2001

MEMORANDUM FOR Dr. Robert Ebeling, CEERD-ID-P, US Army Engineer Research and Development Center, 3909 Halls Ferry Road, Vicksburg, MS, 39180-6199

SUBJECT: Corps of Engineers Hazard Reduction Program - Powerhouse Evaluation Criteria

1. The Corps of Engineers Hazard Reduction Program (CEHRP) was implemented to assure the safety of all occupants in USACE owned structured in accordance with Executive Order 12941 and Public Law 101614, National Earthquake Hazard Reduction Program (NEHRP). As required in EO 12941, the Interagency Committee on Seismic Safety in Construction (ICSSC) adopted minimum life safety standards for all federally owned buildings and building type structures based on existing Federal Emergency Management Agency (FEMA) guidance documents.

2. In complying with the minimum standards adopted by the ICSSC and the intent of those standards the drawings of many of the USACE owned powerhouses were reviewed, the districts responsible for those powerhouses were surveyed, a number of studies were performed, and existing seismic criteria was reviewed. With few exceptions, powerhouse superstructures were considered non-critical features. Specifically, failure of the powerhouse superstructure is not likely to result in failure of the dam and consequently loss of life downstream. This means that site specific earthquake assessments are not required and are only recommended if it is likely that the site specific assessment will reduce the earthquake demand on a structure. In addition, it allows the use of progressively more complex evaluation procedures as the specific situation warrants.

3. However, for those powerhouses not remotely operated, no reasonable justification to establish a performance level or evaluation criteria less than that required for any occupied building could be found. To comply with the intent of the minimum ICSSC standards, the FEMA building 
evaluation criteria adopted as the minimum life safety standard (FEMA 178, FEMA 310) were reviewed and the recommended rehabilitation criteria (FEMA 273, FEMA 274, and FEMA 356) were consulted and consolidated to a single draft criteria document with progressively more complex evaluation procedures.

4. The powerhouse superstructure evaluations conducted and funded by our office were based on a design level earthquake with a collapse prevention check for the maximum considered earthquake. The design level earthquake used was approximately a 1000 year probabilistic earthquake event based on the 1997 NEHRP maps. In addition, in accordance with FEMA 273 and FEMA 274 a collapse prevention check was performed using the Maximum Considered Earthquake based on the 1997 NEHRP maps. On these maps the Maximum Considered Earthquake corresponds to either a 2475-year event, or in zones near major active faults (i.e. California) to either the smaller of the 2475-year event or $150-$ percent of the mean ground motion for a deterministic event (i.e. Maximum Credible Earthquake). The decision to use of the 1997 NEHRP maps instead of the maps shown in ER 1110-2-1806 was based on the fact that this was the latest balloted consensus version, the recommendations of several industry consultants some of whom were involved in the development of the maps, and the FEMA reporting requirements. The seismicity of all buildings and structures in FEMA 360 (the report to Congress) were required to reflect the 1997 NEHRP maps.

5. The evaluation of St. Steven's Hydropower Plant in South Carolina performed by our office for the design level earthquake described above resulted in the conclusion that the powerhouse does not meet the recommended performance level, the minimum life safety standard required by the ICSSC., or the basic safety objective outlined in FEMA 356 and TI 5-809.

6. Based on discussions with Dr. Ebeling and his review of the criteria used in our evaluations, the seismic stability evaluation conducted by CEERD of the St. Steven's Hydropower Plant is consistent with the FEMA 356 (basic safety objective, collapse prevention) seismic analysis procedures and consistent with the methodology used in the CEHRP powerhouse evaluations. 


\author{
Ms Helen Petersen \\ Structural Engineer \\ CEHRP Program Manager
}




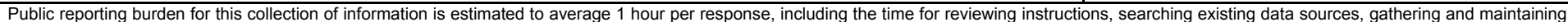

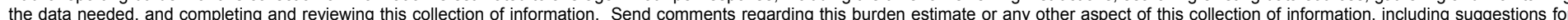

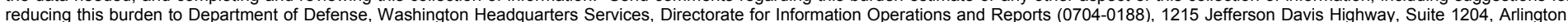

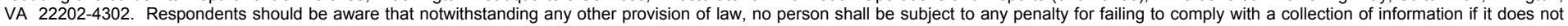
display a currently valid OMB control number. PLEASE DO NOT RETURN YOUR FORM TO THE ABOVE ADDRESS.

\begin{tabular}{l|l} 
1. REPORT DATE (DD-MM-YYYY) & 2. REPORT TYPE
\end{tabular}

February 2002 (Revised Nov 2006) $\quad$ Final report

4. TITLE AND SUBTITLE

Seismic Stability of St. Stephen Hydropower Plant, South Carolina

3. DATES COVERED (From - To)

5a. CONTRACT NUMBER

Seismic Stability of St. Stephen Hydropower Plant, South Carolina

\section{AUTHOR(S)}

5b. GRANT NUMBER

Robert M. Ebeling, Robert L. Hall, Ralph W. Strom, Donald E. Yule, Mostafiz Chowdhury

5c. PROGRAM ELEMENT NUMBER

5d. PROJECT NUMBER

5e. TASK NUMBER

5f. WORK UNIT NUMBER

7. PERFORMING ORGANIZATION NAME(S) AND ADDRESS(ES)

Information Technology Laboratory and Geotechnical and Structures Laboratory, U.S.

Army Engineer Research and Development Center, 3909 Halls Ferry Road, Vicksburg, MS

39180-6199; and 9474 S.E. Carnaby Way, Portland, OR 97266

8. PERFORMING ORGANIZATION REPORT NUMBER

ERDC LR-02-1

9. SPONSORING / MONITORING AGENCY NAME(S) AND ADDRESS(ES)

10. SPONSOR/MONITOR'S ACRONYM(S)

U.S. Army Corps of Engineers

Washington, DC 20314-1000

11. SPONSOR/MONITOR'S REPORT NUMBER(S)

12. DISTRIBUTION / AVAILABILITY STATEMENT

Approved for public release; distribution is unlimited.

\section{SUPPLEMENTARY NOTES}

\section{ABSTRACT}

A performance-based analysis was used to assess the seismic performance of St. Stephen Powerhouse erection bay. Two site-specific design response spectra were used to evaluate the structure. These included a 2,475-year probabilistic earthquake event and a deterministic Maximum Credible Earthquake plus one standard deviation event. The St. Stephen Powerhouse superstructure is vulnerable to collapse for earthquake hazards with return periods greater than 500 years. The structure does not meet the basic safety objective (collapse prevention) of the Federal Emergency Management Agency "Prestandard and Commentary for the Seismic Rehabilitation of Buildings," FEMA 356-357.

\section{SUBJECT TERMS}

Dynamic analysis

Earthquake

16. SECURITY CLASSIFICATION OF:

a. REPORT

UNCLASSIFIED
Performance-based analysis

Powerhouse

rowerhouse

b. ABSTRACT
UNCLASSIFIED

c. THIS PAGE

UNCLASSIFIED

Response spectrum

Seismic stability evaluation

17. LIMITATION OF ABSTRACT
18. NUMBER OF PAGES

74 19a. NAME OF RESPONSIBLE PERSON

19b. TELEPHONE NUMBER (include area code) 